\title{
Improved landslide-tsunami prediction: Effects of block model parameters and slide model
}

\author{
Valentin Heller $^{1}$ and Johannes Spinneken ${ }^{1}$ \\ Received 10 November 2012; revised 9 January 2013; accepted 27 January 2013; published 26 March 2013.
}

[1] Subaerial landslide-tsunamis and impulse waves are caused by mass movements impacting into a water body, and the hazards they pose have to be reliably assessed. Empirical equations developed with physical Froude model studies can be an efficient method for such predictions. The present study improves this methodology and addresses two significant shortcomings in detail for the first time: these are the effect of three commonly ignored block model parameters and whether the slide is represented by a rigid block or a deformable granular material. A total of 144 block slide tests were conducted in a wave flume under systematic variation of three important block model parameters, the slide Froude number, the relative slide thickness, and the relative slide mass. Empirical equations for the maximum wave amplitude, height, and period as well as their evolution with propagation distance are derived. For most wave parameters, remarkably small data scatter is achieved. The combined influence of the three block model parameters affects the wave amplitude and wave height by up to a factor of two. The newly derived equations for block slides are then related to published equations for granular slides. This comparison reveals that block slides do not necessarily generate larger waves than granular slides, as often argued in the technical literature. In fact, it is shown that they may also generate significant smaller waves. The new findings can readily be integrated in existing hazard assessment methodologies, and they explain a large part of the discrepancy between previously published data.

Citation: Heller, V., and J. Spinneken (2013), Improved landslide-tsunami prediction: Effects of block model parameters and slide model, J. Geophys. Res. Oceans, 118, 1489-1507, doi:10.1002/jgrc.20099.

\section{Introduction}

\subsection{Overview}

[2] Subaerial landslide-generated impulse waves, also called landslide-tsunamis if they occur in an ocean, are generated by mass movements such as landslides, rock falls, shore instabilities, or glacier calving impacting into a water body. The most devastating examples include the 1958 Lituya Bay case where a landslide-tsunami destroyed the forest up to a run-up height of $524 \mathrm{~m}$ above mean sea level [Miller, 1960], and the 1963 Vaiont case in Northern Italy, where an impulse wave overtopped a dam by more than $70 \mathrm{~m}$ and caused about 2000 casualties [Müller, 1964]. Many further examples of subaerial landslide-tsunamis and impulse waves are summarized by Slingerland and Voight [1979] who address cases worldwide, Huber [1982] who focuses on events in Switzerland, and Panizzo et al. [2005a] who describe cases in Italy. These reviews are a reminder of how

\footnotetext{
${ }^{1}$ Department of Civil and Environmental Engineering, Imperial College London, London, UK.

Corresponding author: V. Heller, Department of Civil and Environmental Engineering, Imperial College London, London SW7 2AZ, UK. (v.heller@ imperial.ac.uk)

(C)2013. American Geophysical Union. All Rights Reserved. 2169-9275/13/10.1002/jgrc.20099
}

frequently such waves occur, particularly in mountainous countries, fjords, and at volcanic islands.

[3] Subaerial landslide-tsunamis (for simplicity this term also includes impulse waves hereafter) need to be reliably predicted on many occasions to reduce risk to both humans and infrastructure. Such occasions include the planning and operation phases of reservoirs [Fuchs et al., 2011], or in general when a slide starts to creep above a water body such as in the Vaiont case [Müller, 1964]. Field studies deliver valuable traces of tsunamis such as run-up heights or slide deposits [Miller, 1960; Watt et al., 2012]; however, there are few direct observations of the waves themselves. Both physical model studies [Walder et al., 2003; Fritz et al., 2004; Panizzo et al., 2005b; Heller and Hager, 2010] and numerical studies [Quecedo et al., 2004; Liu et al., 2005; Lynett and Liu, 2005; Løvholt et al., 2008; Abadie et al., 2010; Giachetti et al., 2011; Abadie et al., 2012] are therefore essential for landslide-tsunami hazard assessment. Analytical studies [Di Risio and Sammarco, 2008] are much less frequently conducted. Perhaps the most accurate method in predicting the wave features remains a prototype-specific physical model study that can reproduce all geometric and bathymetric details [Western Canada Hydraulic Laboratories, 1970; Fuchs et al., 2011].

[4] Generic physical model studies systematically vary parameters (slide properties, hill slope angle, water depth), which may be estimated a priori for real-world events, and 
express the unknown wave parameters (amplitude, height, period) as a function of these parameters. The resulting empirical equations can be very efficient in predicting future events [Heller et al., 2009], and are often the most straightforward method if time is limited. At the very least, such equations can help to determine whether or not a prototype-specific numerical or physical model study is required, these latter methods being both considerably more expensive and time consuming. The present work concentrates on empirical equations to improve their capabilities in realworld predictions.

[5] A number of empirical formulae have been proposed to predict subaerial landslide-tsunamis. Empirical equations for the maximum (subscript M) wave amplitude $a_{\mathrm{M}}$ were presented by Noda [1970], Slingerland and Voight [1979], Monaghan and Kos [2000], Walder et al. [2003], Fritz et al. [2004], and Zweifel et al. [2006]. The evolution of $a_{\mathrm{M}}$ with the distance $x$ from the slide impact zone has been considered by Zweifel et al. [2006], Ataie-Ashtiani and Nik-Khah [2008], and by Mohammed and Fritz [2012] for the primary wave. The majority of these equations were developed based on tests conducted in wave channels, where 2-D wave propagation occurs in $x$, the longitudinal direction of the channel. Equations for the maximum wave height $H_{\mathrm{M}}$ and/or the maximum wave height evolution $H(x)$ are available for 2-D wave propagation from Kamphuis and Bowering [1972] and Huber and Hager [1997], and from Huber and Hager [1997] and Panizzo et al. [2005b] for a wave basin geometry, where 3-D wave propagation occurs in half circles in $r$, the radial direction. The prediction of the maximum wave period $T_{\mathrm{M}}$ is more challenging. Nevertheless, Kamphuis and Bowering [1972], Panizzo et al. [2005b], Ataie-Ashtiani and Nik-Khah [2008], and Mohammed and Fritz [2012] proposed equations to predict the wave period. Heller et al. [2009] (2-D and 3-D) and Heller and Hager [2010] (2-D) proposed empirical equations for all three parameters $a_{\mathrm{M}}, H_{\mathrm{M}}$, and $T_{\mathrm{M}}$, including their evolution with $x$. This is important in an engineering context, because all these parameters are required for the prediction of the run-up height or forces on dams. Methods to transform parameters deduced in 2-D to 3-D were also suggested [Huber and Hager, 1997; Heller et al., 2009, 2012].

[6] A disadvantage of empirical equations is that they often result in considerable differences in wave predictions. For instance, Heller and Hager [2010] directly compared the outcome of their predictive equations with 11 studies for the Lituya Bay case and observed discrepancies in tsunami height by up to a factor of 5.6. Similar variations were found by Watt et al. [2012] who used four empirical equations for the wave amplitude to investigate scenarios of landslidetsunamis generated around the volcanic island Montserrat. Slingerland and Voight [1979] even found discrepancies of up to a factor of 60 between 2-D and 3-D studies. The potential reasons for such substantial discrepancies are detailed in appendix A. These include model effects (water body geometry, slide model, block model parameters, wave parameter definition, and violation of parameter limitations), measurement effects (different measurement systems or locations), scale effects, and human error. The aim of the present work is to quantify discrepancies (a) due to three commonly ignored block model parameters and (b) between models in which the slide is represented by a rigid block or granular material. The firm aim is to improve landslide-tsunami predictions for real-world examples.

\subsection{Focus of the Present Work}

[7] A first focus of this study is the systematic investigation of three block model parameters with new subaerial landslidetsunami experiments. Heller and Kinnear [2010] pointed out that these three parameters may be responsible for a significant part of the discrepancies between studies because they are not considered in any predictive equation to date. These three block model parameters, as illustrated in Figure 1, are: (i) The blockage ratio $b_{\mathrm{s}} / b$, defined as the slide (subscript s) width $b_{\mathrm{s}}$ relative to the channel width $b$, (ii) The slide front angle $\phi$ and, (iii) The transition type at the slope toe.

[8] The transition type specifies how the transition in slope from the hill slope to the horizontal channel bottom ( $45^{\circ}$ in the present study) is modeled (Figure 1). Table 1 summarizes a number of block model studies conducted in wave channels (2-D) including their values for (i) to (iii). All previous studies in Table 1 are based on a single value for $b_{\mathrm{s}} / b$ (with extremes $b_{\mathrm{s}} / b=0.526$ and 1 , which is strictly speaking impossible because a block with $b_{\mathrm{s}}=b$ would not move), and one transition type (with extremes abrupt stop with buffer and smooth rounded). The overall variation of the slide front angle $\phi$ was between $28.5^{\circ}$ and $113.5^{\circ}$. The only study to date which varied $\phi$ is Kamphuis and Bowering [1972]. They found that the slide front orientation angle $\phi+\alpha$, with the slide impact angle $\alpha$ (Figure 1), has a direct impact on the wave height. However, despite their findings, this effect was not included in their empirical equations for the wave height, only in its limitations. Consequently, no previous study includes the effects of (i) to (iii) in empirical equations; this likely leading to a source of discrepancies between different block model studies. Note that even though some model configurations (abrupt slide stop, blockage ratio) may rather not occur in real-world examples, it is important to investigate these extreme cases to understand which consequences small model changes can have on the tsunami features.

[9] A second focus of the present study is to develop a comprehensive understanding of the effect of the slide model (rigid block versus granular slide) on the wave characteristics. Physical model studies use either a block slide model [Kamphuis and Bowering, 1972; Monaghan and Kos, 2000; Walder et al., 2003; Panizzo et al., 2005b; Heller et al., 2012] or a granular slide model [Huber and Hager, 1997; Fritz et al., 2004; Zweifel et al., 2006; Heller and Hager, 2010; Mohammed and Fritz, 2012]. Both idealizations have their justification in practice because a wide variety of mass movement types is observed in nature including slide, flow, fall, topple, and spread [Cruden and Varnes, 1996].

[10] The effect of the slide model was only investigated for limited parameter ranges and a small number of tests have been carried out to date. The previous studies addressing this effect all concluded that blocks generate larger waves than granular slides [cf. Heller and Kinnear, 2010]. Based on a literature review, Slingerland and Voight [1979] stated that the 2-D vertical box-drop tests from Noda [1970] generate up to four times larger waves when compared to 3-D tests where bags filled with iron and lead were used. However, the major part of this difference may be attributed to the effect of the 


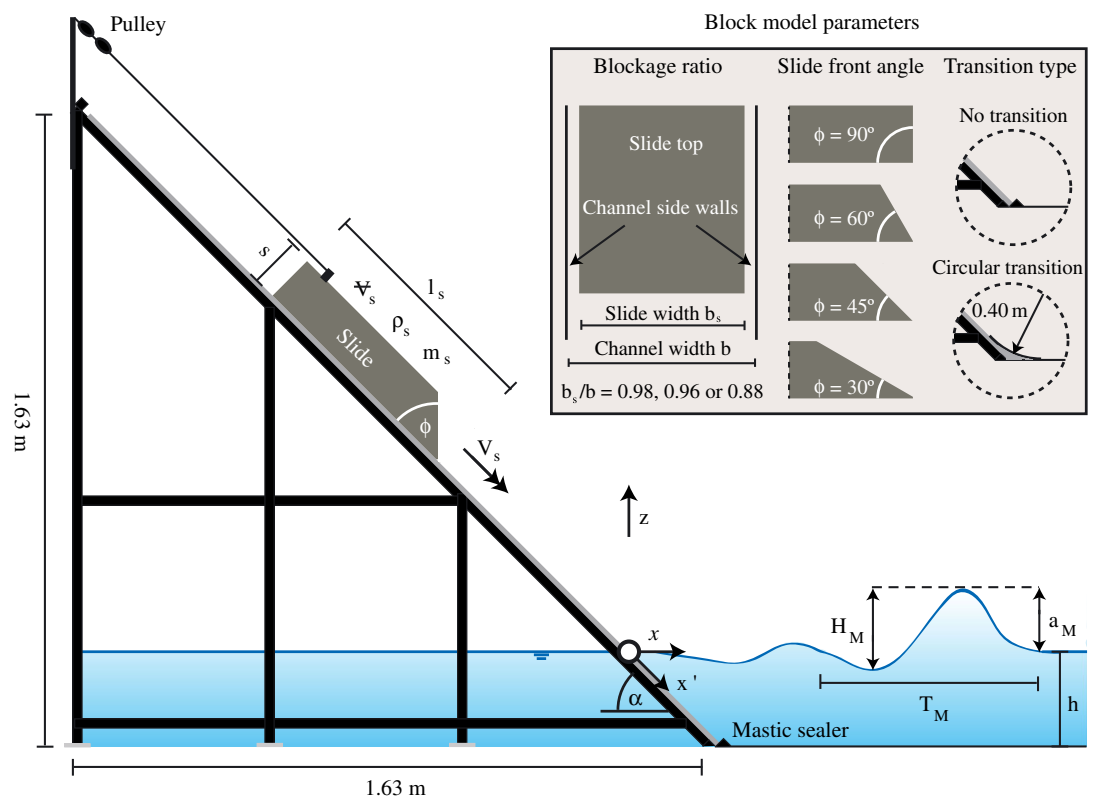

Figure 1. Ramp with pulley system, slide, and wave parameters for the case without transition, and definition of the three investigated block model parameters.

Table 1. 2-D Block Model Studies ${ }^{\mathrm{a}}$

\begin{tabular}{|c|c|c|c|c|c|c|c|}
\hline Study & $b(\mathrm{~m})$ & $b_{\mathrm{s}}(\mathrm{m})$ & $b_{\mathrm{s}} / b(-)$ & $\alpha\left({ }^{\circ}\right)$ & $\phi\left({ }^{\circ}\right)$ & $\phi+\alpha\left(^{\circ}\right)$ & Transition Type \\
\hline $\begin{array}{l}\text { Wiegel et al. }[1970] / \\
\text { Noda }[1970]\end{array}$ & 0.305 & N.A. & N.A. & 90 & 90 & 180 & None \\
\hline $\begin{array}{l}\text { Kamphuis and } \\
\text { Bowering [1972] }\end{array}$ & 1.000 & N.A. & N.A. & 19.9-90 & $28.5-113.5$ & $60-180$ & None \\
\hline Heinrich [1992] & 0.550 & 0.550 & 1.000 & 45 & 45 & 90 & $\begin{array}{l}\text { Abrupt stop with } \\
\text { buffer }\end{array}$ \\
\hline Monaghan and Kos [2000] & 0.400 & 0.390 & 0.975 & 90 & 90 & 180 & None \\
\hline Panizzo et al. [2002] & 0.110 & N.A. & N.A. & 90 & 90 & 180 & None \\
\hline Monaghan et al. [2003] & 0.400 & 0.385 & 0.963 & 10.1 & 90 & 100.1 & None \\
\hline Walder et al. [2003] & 0.285 & 0.150 & 0.526 & $11.2-19.5$ & 32 & $43.2-51.5$ & Curved smoothly \\
\hline Zweifel [2004] & 0.500 & 0.490 & 0.980 & 45 & 90 & 135 & None \\
\hline Scelevik et al. [2009] & 0.510 & 0.450 & 0.882 & 35 & 45 & 80 & Smooth rounded \\
\hline Heller et al. [2012] & 0.250 & 0.240 & 0.960 & 45 & 45 & 90 & Circular \\
\hline This study & 0.600 & $0.59,0.58,0.53$ & $0.98,0.96,0.88$ & 45 & $30,45,60,90$ & $75,90,105,135$ & $\begin{array}{l}\text { None with stopper, } \\
\text { circular }\end{array}$ \\
\hline
\end{tabular}

${ }^{\mathrm{a}} b$ is channel width, $b_{\mathrm{s}}$ slide width, $b_{\mathrm{s}} / b$ blockage ratio, $\alpha$ slide impact angle, $\phi$ slide front angle, and $\phi+\alpha$ slide front orientation angle; N.A. indicates not available [after Heller and Kinnear, 2010].

water body geometry rather than to the slide model (appendix A). Ataie-Ashtiani and Nik-Khah [2008] found that granular slides generate up to $35 \%$ smaller wave amplitudes and up to $30 \%$ larger wave periods than block slides in a wave channel considerably wider than the slide width. Zweifel [2004] generated impulse waves with both block and granular slides. He conducted eleven tests with a $0.335 \mathrm{~m}$ long, $0.205 \mathrm{~m}$ high, and $0.490 \mathrm{~m}$ wide block (block model parameters $b_{\mathrm{s}} / b=0.980$, $\phi=90^{\circ}$, and no transition, Table 1$)$. The maximum wave amplitudes $a_{\mathrm{M} \text {,block }}$ generated by the block (subscript block) were compared with the corresponding granular (subscript granular) values $a_{\mathrm{M} \text {,granular }}$ calculated with Zweifel's [2004] empirical equation based on 86 tests. He observed up to 7.4 times larger wave amplitudes generated by block slides than by the corresponding granular slides. The present study investigates the effect of the slide model with a much larger data set and for six, rather than one wave parameter, to achieve a more comprehensive insight. This investigation is based on new block slide data and already published granular slide tests.

[11] This article is organized as follows: section 2 introduces the physical model employed for the new block model tests. Sections 3.1 and 3.2 present the experimental results. The effects of the three block model parameters (i) to (iii) are then quantified (section 3.2.2) and included in empirical equations (section 3.3). In section 4, the wave features of the new block model tests are compared to data from granular slide tests and their application to real-world cases is addressed. The most 
relevant points are summarized in the conclusions (section 5). Reasons for discrepancies between different model studies are addressed in appendix A and appendix B presents an application example.

\section{Physical Model}

[12] The set-up and measurement system employed in the present study is identical to that used in Heller and Spinneken [2012]. The experiments, based on Froude similarity, were conducted in the Coastal Wave Flume of the Hydrodynamics Laboratory of the Department of Civil and Environmental Engineering at Imperial College London. This flume is $24.5 \mathrm{~m}$ long, $b=0.600 \mathrm{~m}$ wide, and $1.0 \mathrm{~m}$ high. The hill slope ramp shown in Figure 1 was built with the front inclined at $\alpha=45^{\circ}$, and it was placed at one end of the flume. The ramp's front surface consisted of PVC sheets with a stainless steel guide in the center matching a groove in the slide bottom to assure that the slide, used to generate the tsunamis, stayed in the channel center during impact. The slides were moved in the raised position with a pulley system and released with a mechanism fitted on the slide surface. Silicon sealant was filled in the gaps between the PVC sheets and flume walls. The glass bottom in the immediate slide impact zone was protected with a $1 \mathrm{~m}$ long and $2 \mathrm{~mm}$ thick rubber sheet covered with a $2 \mathrm{~mm}$ thick stainless steel plate. In addition, mastic sealer was placed at the bottom of the slope to assure that the slide came to an abrupt rest in the scenario without transition, such as in the study of Heinrich [1992] (Table 1). The circular-shaped transition in other scenarios was made of an aluminum sheet bent to an eighth of a circle of radius $0.400 \mathrm{~m}$ (Figure 1).

[13] The tsunamis were generated by block slides made of PVC. The slide parameters are defined in Figure 1, namely the slide volume $V_{\mathrm{s}}$, the slide density $\rho_{\mathrm{s}}$, the slide mass $m_{\mathrm{s}}$, the slide thickness $s$, the slide length $l_{\mathrm{s}}$, the slide front angle $\phi$, the slide centroid impact velocity $V_{\mathrm{s}}$, and the slide width $b_{\mathrm{s}}$. The still water depth $h$ is measured at the slope toe. The coordinate origin $(x ; z)$ is defined at the intersection of the still water surface and the hill slope ramp. This is also the origin of the $x^{\prime}$-coordinate along the hill slope. The most relevant wave parameters are the maximum wave amplitude $a_{\mathrm{M}}$, the maximum wave height $H_{\mathrm{M}}$, and the maximum wave period $T_{\mathrm{M}}$; the latter being defined as the time between two consecutive wave zero up-crossings. Note that $H_{\mathrm{M}}$ and $T_{\mathrm{M}}$ are defined at the same position (or wave probe) and for the same wave within the wave train as $a_{\mathrm{M}}$ was measured. Similarly, the evolution of the wave amplitude $a(x)$, the height $H(x)$, and the period $T(x)$ as a function of distance $x$ are deduced for the same wave in the wave train where $a_{\mathrm{M}}$ was observed. This convention should prevent the mixing of parameters from different waves in the wave train or locations in subsequent engineering calculations; the computation of the run-up height or force on a dam being prime examples.

[14] The test program included 144 tests; their experimental parameters and the slide features being shown in Table 2. For all experiments the slide thickness was $s=0.120 \mathrm{~m} \pm 0.4 \%$, the slide volume $\forall_{\mathrm{s}}=0.0373 \mathrm{~m}^{3} \pm 0.9 \%$, and the slide mass $m_{\mathrm{s}}=57.23 \mathrm{~kg} \pm 0.4 \%$, resulting in a slide density $\rho_{\mathrm{s}} \approx 1534 \mathrm{~kg} / \mathrm{m}^{3} \pm 1.0 \%$. These constant values were achieved despite the variation of the slide width $b_{\mathrm{s}}$ or slide front angle $\phi$. For each investigated $\phi$ a slide base was manufactured and PVC additions were mounted at the sides and/or rear of these bases to vary $b_{\mathrm{s}}$. The total volume of base plus additions was constant. This is illustrated in Figure 2 for the slide used for tests with $\phi=90^{\circ}$.

[15] The test program included the three blockage ratios $b_{\mathrm{s}} / b=0.98,0.96$, and 0.88 (Figure 1, Tables 1 and 2). More extreme values were excluded because wall effects may become too dominant for slides with $b_{\mathrm{s}} / b>0.98$, and 3-D effects may be significant for $b_{\mathrm{s}} / b<0.88$. The test program further included four slide front angles $\phi=30,45,60$, and $90^{\circ}$, and two transition types (Figure 1) in order to reflect the full range of parameters applied in previous studies (Table 1). Two water depths namely $h=0.300$ and $0.600 \mathrm{~m}$ were selected to investigate wide parameter ranges and different wave types. Note that the water depth was in the range $h \geq 0.200 \mathrm{~m}$ where Heller et al. [2008] found that scale effects relative to the maximum wave amplitude are insignificant (appendix A). The slide front release positions were $x^{\prime}=0.00,-0.50$, and $-1.10 \mathrm{~m}(h=0.300 \mathrm{~m})$ and $0.00,-0.30$, and $-0.70 \mathrm{~m}(h=0.600 \mathrm{~m})$, resulting in slide centroid impact velocities of $0.59 \leq V_{\mathrm{s}} \leq 3.56 \mathrm{~m} / \mathrm{s}$.

[16] A set of dimensionless parameters was introduced based upon the definitions in Heller and Hager [2010]. This includes the slide Froude number $0.34 \leq \mathrm{F}=V_{\mathrm{s}} /(g h)^{1 / 2} \leq 2.07$ with gravitational acceleration $g$, the relative slide thickness $0.20 \leq S=s / h \leq 0.40$, relative slide mass $0.27 \leq M=$ $m_{\mathrm{s}} /\left(\rho_{\mathrm{w}} b_{\mathrm{s}} h^{2}\right) \leq 1.21$ with the water (subscript w) density $\rho_{\mathrm{w}}$, and hill slope angle $\alpha=45^{\circ}$. These dimensionless parameters were combined to the impulse product parameter $0.16 \leq \mathrm{P}=$ $\mathrm{FS}^{1 / 2} M^{1 / 4}\{\cos [(6 / 7) \alpha]\}^{1 / 2} \leq 1.19$. The parameter $\mathrm{P}$ is related to the streamwise slide momentum flux component and was successfully used to predict most wave characteristics in the study of Heller and Hager [2010].

[17] The measurement system included a laser distance sensor (LDS) to determine the slide centroid impact velocity $V_{\mathrm{s}}$. A PVC strip with holes at constant intervals was bonded on the top surface of the slides (Figure 2), and this strip was scanned with the LDS at $128 \mathrm{~Hz}$. The velocity $V_{\mathrm{S}}$ was then calculated with the spatial and temporal interval between two holes before and after the hole corresponding to the slide centroid impact location. This methodology resulted in highly consistent $V_{\mathrm{s}}$ values, as shown in Figure 3, for all tests conducted for the parameter combination with no transition and $\phi=90^{\circ}$. Note that the tests of the present study are compared with granular tests from Heller and Hager [2010] in section 4, such that the identical method to measure $V_{\mathrm{s}}$ was applied herein. In predicting real-world cases, the slide centroid impact velocity $V_{\mathrm{s}}$ may be estimated more easily than the slide front impact velocity. This further underpins the choice of this parameter. The wave features were recorded at $128 \mathrm{~Hz}$ using seven resistance type wave probes located at relative distances $x / h=3.0,5.0,7.5,9.7$, 15.0, 25.0, and 40.0, for $h=0.300 \mathrm{~m}$, and 3.0, 5.0, 7.5, $10.0,15.0,20.0$, and 29.5, for $h=0.600 \mathrm{~m}$ (Table 2). Photographs of selected runs were taken with a digital camera.

[18] Some tests were repeated three times in the prestudy of Heller and Spinneken [2012] to investigate the repeatability of the wave parameters $a, H$, and $T$. Deviations of individual tests from the mean of all three tests were typically less than $\pm 4 \%$, with values for the maximum deviations lying within $\pm 10 \%$. The scatter of correlated data is often in the order of 
HELLER AND SPINNEKEN: IMPROVED LANDSLIDE-TSUNAMI PREDICTION

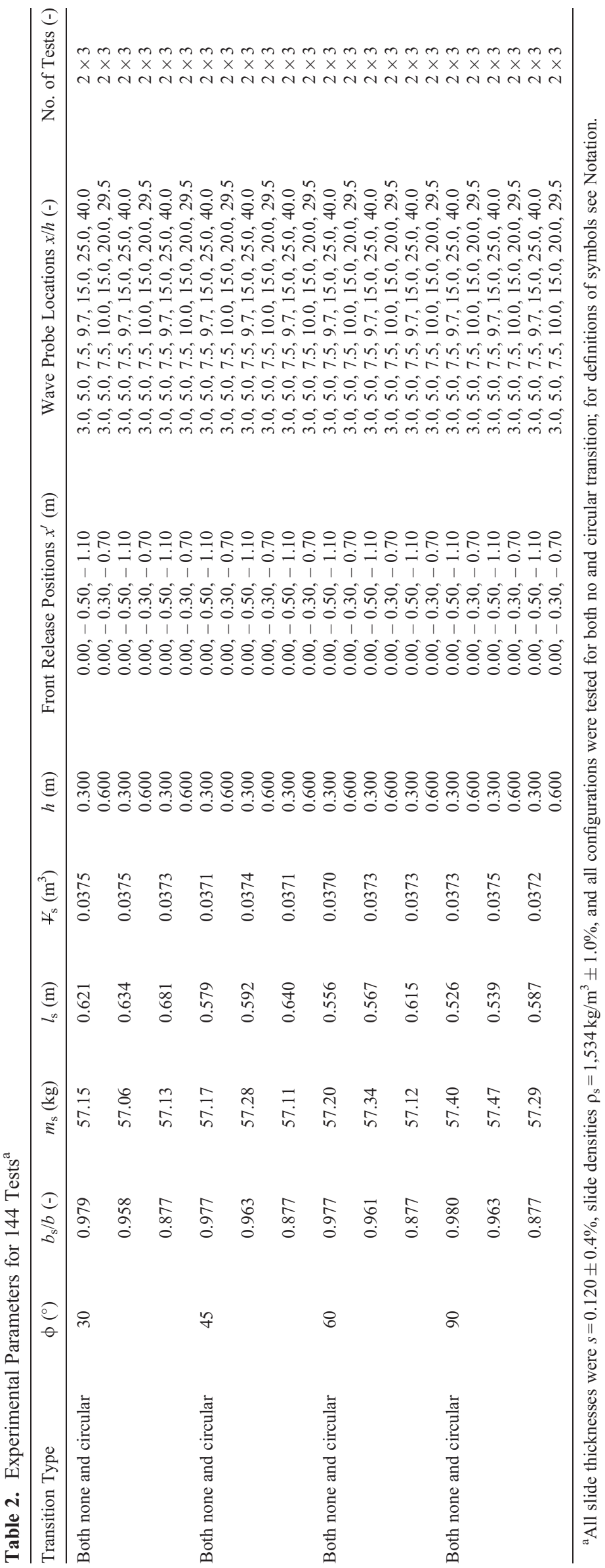




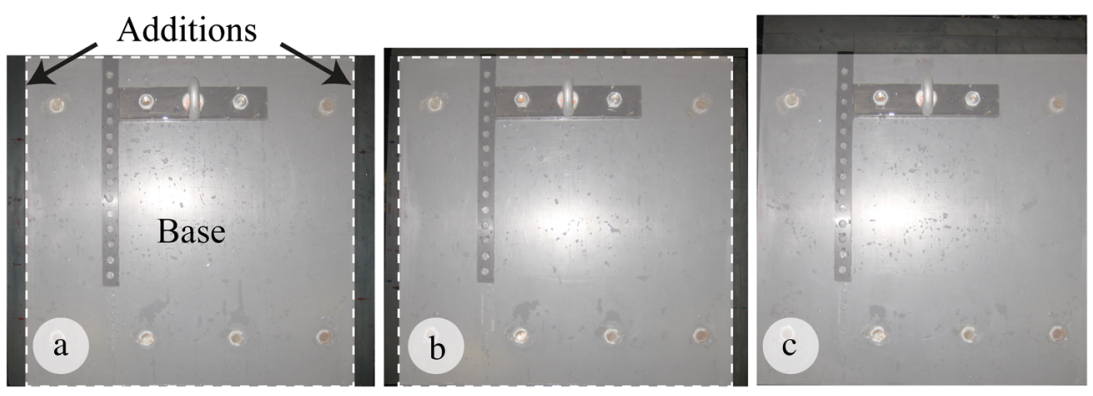

Figure 2. Plane view of slides for tests with $\phi=90^{\circ}$ consisting of a base (marked in white) and of additions mounted to the sides and/or rear to vary the blockage ratios $b_{\mathrm{s}} / b$ from (a) 0.98 , (b) 0.96 to (c) 0.88 , with the slide volume held constant; fittings on the slide were used to connect the pulley system and crane [after Heller and Spinneken, 2012].

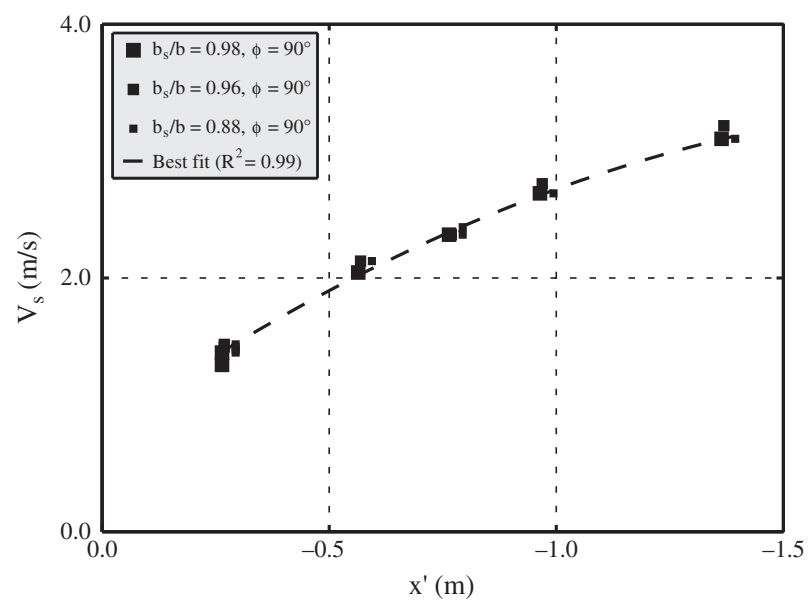

Figure 3. Slide centroid impact velocity $V_{\mathrm{s}}$ versus centroid release position $x^{\prime}$ along the ramp surface for tests without transition and $\phi=90^{\circ}$ [after Heller and Spinneken, 2012].

$+100 /-50 \%$ relative to $a / h$ or $H / h$ [Walder et al., 2003; Panizzo et al., 2005b], and the results for the wave period are often omitted. Maximum deviations of $\pm 10 \%$ can therefore be considered as relatively small such that each test was only once conducted in the present study.

\section{Experimental Results}

\subsection{Analysis of Selected Block Slide Tests}

[19] Figure 4 shows a series of images, at time increment $0.167 \mathrm{~s}$, of a test without transition (Figures $4 \mathrm{a}$ to $4 \mathrm{e}$ ), and the corresponding test with a circular transition (Figures $4 \mathrm{f}$ to $4 \mathrm{j})$. These sequences illustrate the effect of the transition type for $h=0.300 \mathrm{~m}, \mathrm{~F}=1.47$ (no transition), $\mathrm{F}=1.04$ (circular transition), $S=0.40, M=1.08, b_{\mathrm{s}} / b=0.98$, and $\phi=45^{\circ}$. Note that in both experiments the slide was released from an identical height, but the transition type has a considerable effect on the slide centroid impact velocity $V_{\mathrm{s}}$, and consequently on $\mathrm{F}$. This is due to the dynamics of the slide nose, which is still moving on the $45^{\circ}$ slope for tests without transition while $V_{\mathrm{s}}$ is deduced, whereas the nose already propagates on the circular transition for the remaining tests. In the latter tests, the slide decelerates due to the impact into the water and the circular transition, while in the former tests only the water resistance has a decelerating effect. This point is further investigated in section 3.2.2.

[20] The slide front is slightly submerged at the beginning of both photo sequences in Figures $4 \mathrm{a}$ and $4 \mathrm{f}$, respectively. On the next frame, $0.167 \mathrm{~s}$ later, the slide in the experiment without transition has already reached its final position (Figure 4b) and stops abruptly due to the mastic sealer at the slope toe (Figure 1). The rear part of the slide stays above the calm water surface and only the front part is actively involved in wave generation. In fact, this was the main reason for also conducting tests at $h=0.600 \mathrm{~m}$, where the whole slide submerges, because this is more realistic in real-world situations. On the corresponding frame for the test with transition (Figure 4g), the slide front reaches the end of the circular transition. The two transition types result in different impact craters as seen if Figures $4 \mathrm{~b}$ and $4 \mathrm{~g}$ are compared. The water crater trim detaches from the block in Figure $4 \mathrm{c}$ due to its abrupt deceleration, whereas its lower part attaches in Figure $4 \mathrm{~h}$ and encloses an air pocket on the slide top, which is detrained in Figures $4 \mathrm{i}$ and $4 \mathrm{j}$. Nevertheless, for both transition types the crater collapses outward, and a bore-like wave runs up on the slide top (Figure 4d) or the hill slope (Figure 4i), resulting later in the secondary wave. When comparing Figure 4d with Figure 4i, it can be observed that the water splash, the wave amplitude, and in particular the volume of the primary wave is much larger for the test with circular transition. The impact of the water splash generates a violent two phase air-water mixture when the primary wave crest passes the first wave probe slightly prior to Figures $4 \mathrm{e}$ and $4 \mathrm{j}$. For the case with transition the slide mass finally comes to rest in Figure $4 \mathrm{j}$.

[21] Figure 5 shows the relative water surface displacement $\eta / h$ versus relative time $t(g / h)^{1 / 2}$, with time $t$, for the two tests considered in Figure 4 . The signals were recorded at relative distances 3.0 (Figure 5a), 7.5 (Figure 5b), 15.0 (Figure 5c), and 40.0 (Figure 5d). The difference in wave amplitude is $44 \%$ at $x / h=3.0$, increases with increasing distance from the slide impact zone, and reaches $98 \%$ at $x / h=40.0$. The secondary wave is created by the bore-like wave run-up shown in Figures 4d and 4e, and Figures $4 \mathrm{i}$ and $4 \mathrm{j}$. Both Figures 4 and 5 give a first indication of the critical relevance of the previously unconsidered transition type.

[22] The effect of the slide front angle $\phi$ is illustrated in Figure 6 for tests with $h=0.300 \mathrm{~m}, \mathrm{~F} \approx 1.43, S=0.40$, 

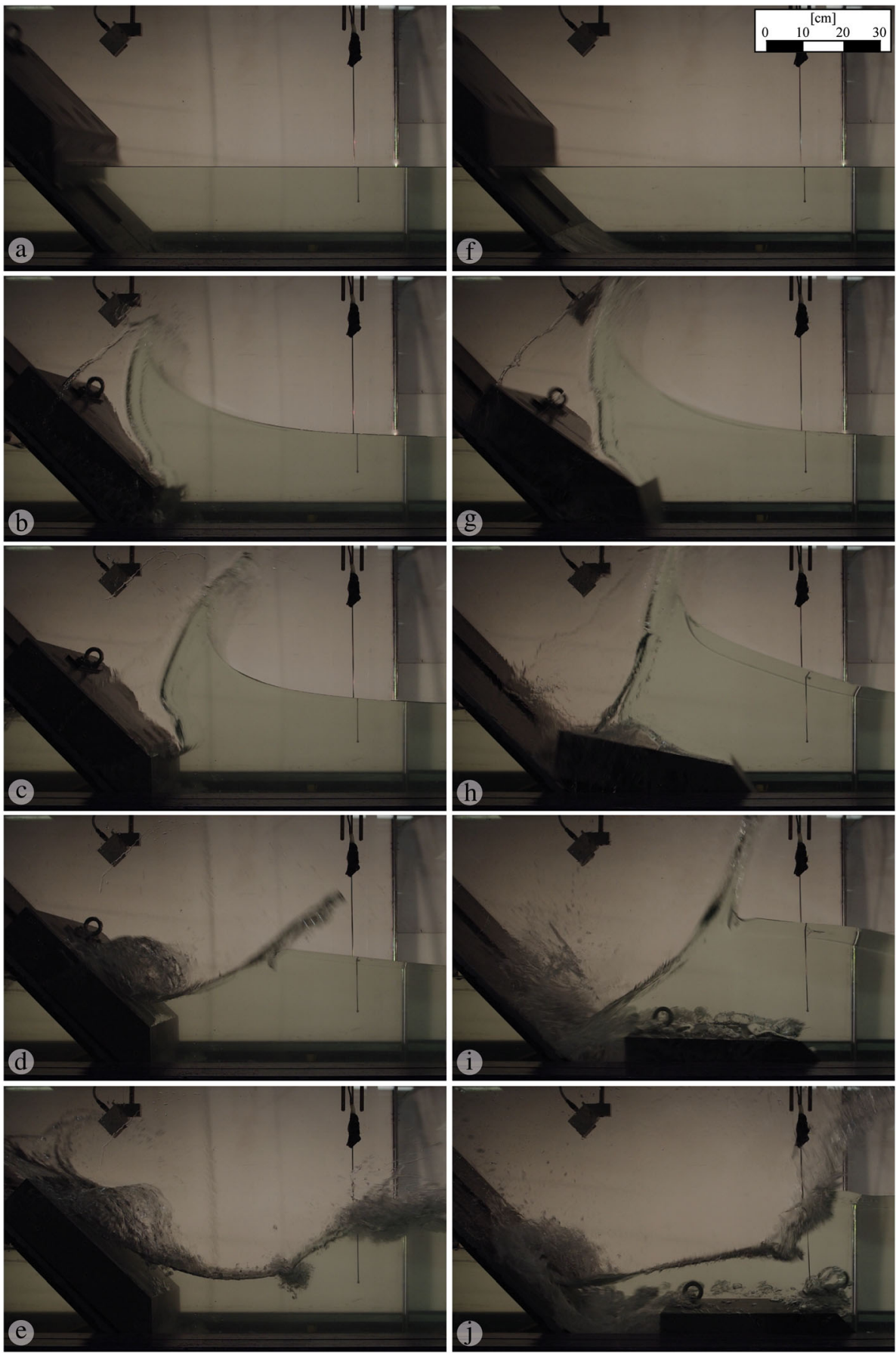

Figure 4. Series of images at time increment $0.167 \mathrm{~s}$ showing the effect of the transition type, without transition (a) to (e) and circular transition (f) to (j), on wave generation for otherwise mostly identical parameters $h=0.300 \mathrm{~m}, \mathrm{~F}=1.47$ (no transition), $\mathrm{F}=1.04$ (circular transition), $S=0.40$, $M=1.08, b_{\mathrm{s}} / b=0.98$, and $\phi=45^{\circ}$; also shown are the LDS and the first wave probe.

$M=1.10, b_{\mathrm{s}} / b=0.96$, and no transition. The slide front angle is $\phi=30^{\circ}$ in Figures $6 \mathrm{a}$ and $6 \mathrm{~b}, \phi=45^{\circ}$ in Figures $6 \mathrm{c}$ and $6 \mathrm{~d}$, and $\phi=90^{\circ}$ in Figures $6 \mathrm{e}$ and $6 \mathrm{f}$. The slide fronts reach the bottom of the hill slope on the frames in Figures 6a, 6c, and $6 \mathrm{e}$, and the primary wave crest passes the first wave probe on Figures $6 \mathrm{~b}, 6 \mathrm{~d}$, and 6f. The slide impact crater changes considerably with $\phi$, and the wave amplitude at the first wave probe also increases with $\phi$. Further affected are the run-ups and splashes, particularly notable if Figures $6 \mathrm{~b}$ and $6 f$ are compared. Most importantly, $\phi$ affects the wave parameters significantly, as further discussed below.

\subsection{Analysis of All Tests}

\subsubsection{Initial Correlations}

[23] Figure 7a shows the relative maximum wave amplitude $a_{\mathrm{M}} / h$ versus slide Froude number $\mathrm{F}$ for all 144 tests. The 

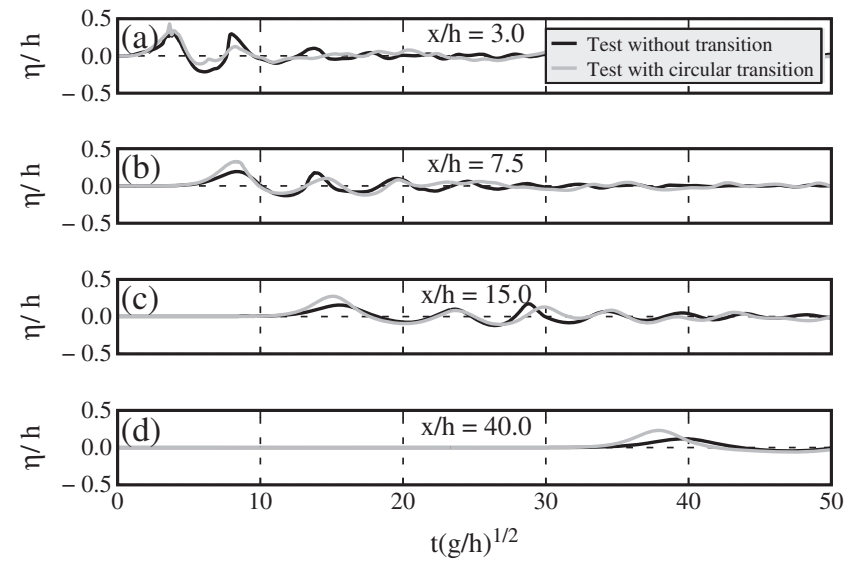

Figure 5. Relative water surface displacement $\eta / h$ of test$\mathrm{s}$ in Figure 4 versus relative time $t(g / h)^{1 / 2}$ at (a) $x / h=3.0$, (b) $x / h=7.5$, (c) $x / h=15.0$, and (d) $x / h=40.0$.

parameter $\mathrm{F}$ was identified in many studies [e.g., Noda, 1970; Fritz et al., 2004; Heller and Hager, 2010] as the most dominant parameter in predicting the amplitude of subaerial landslide-tsunamis. For $77 \%$ of the tests, $a_{\mathrm{M}}$ was observed at the primary wave, whilst for the remaining tests the secondary wave was larger. Black symbols in Figure 7a refer to tests without transition, and dark grey, light grey, and white symbols to tests with circular transition. The slides on the circular transition did not always run out as smoothly as shown in Figures $4 \mathrm{~g}$ to $4 \mathrm{j}$. Mainly depending on the slide impact velocity $V_{\mathrm{s}}$ and the water depth $h$, some slides stopped with their front nose on the transition (dark grey symbols), some with the nose slightly after the transition (light grey symbols) and some run-out smoothly (white symbols). Consequently, the dependency between the slide kinematics and $a_{\mathrm{M}} / h$ is large. However, since the slide run-out distance increases with $\mathrm{F}$ (Figure 7a), this variation is directly incorporated into $\mathrm{F}$.

[24] Generally speaking, tests conducted with a circular transition generate about 50 to $100 \%$ larger waves than tests conducted without transition at water depth $h=0.300 \mathrm{~m}$ (Figure 7a). This effect is much smaller for $h=0.600 \mathrm{~m}$ (tests marked with a grey background in Figure 7). The reason is that the primary wave for $h=0.600 \mathrm{~m}$ has already propagated away from the slide impact zone once the slide reaches the transition such that the effect of the transition type on the primary wave is limited. The different symbols in Figure 7a refer to different slide front angles with $\phi=30^{\circ}(\triangleleft), \phi=45^{\circ}$ (solid triangle), $\phi=60^{\circ}$ (solid diamond), and $\phi=90^{\circ}$ (solid square). The effect of $\phi$ is significant, and tests conducted with $\phi=90^{\circ}$ tend to generate larger waves than tests with $\phi=30^{\circ}$. Finally, the symbol size reflects the blockage ratio, with the largest symbols for $b_{\mathrm{s}} / b=0.98$ and the smallest symbols for $b_{\mathrm{s}} / b=0.88$. Overall, $a_{\mathrm{M}}$ tends to increase with increasing $b_{\mathrm{s}} / b$, which may be readily observed for the three tests conducted at $\mathrm{F} \approx 1$ and $a_{\mathrm{M}} / h \approx 0.4$ in Figure $7 \mathrm{a}$. However,
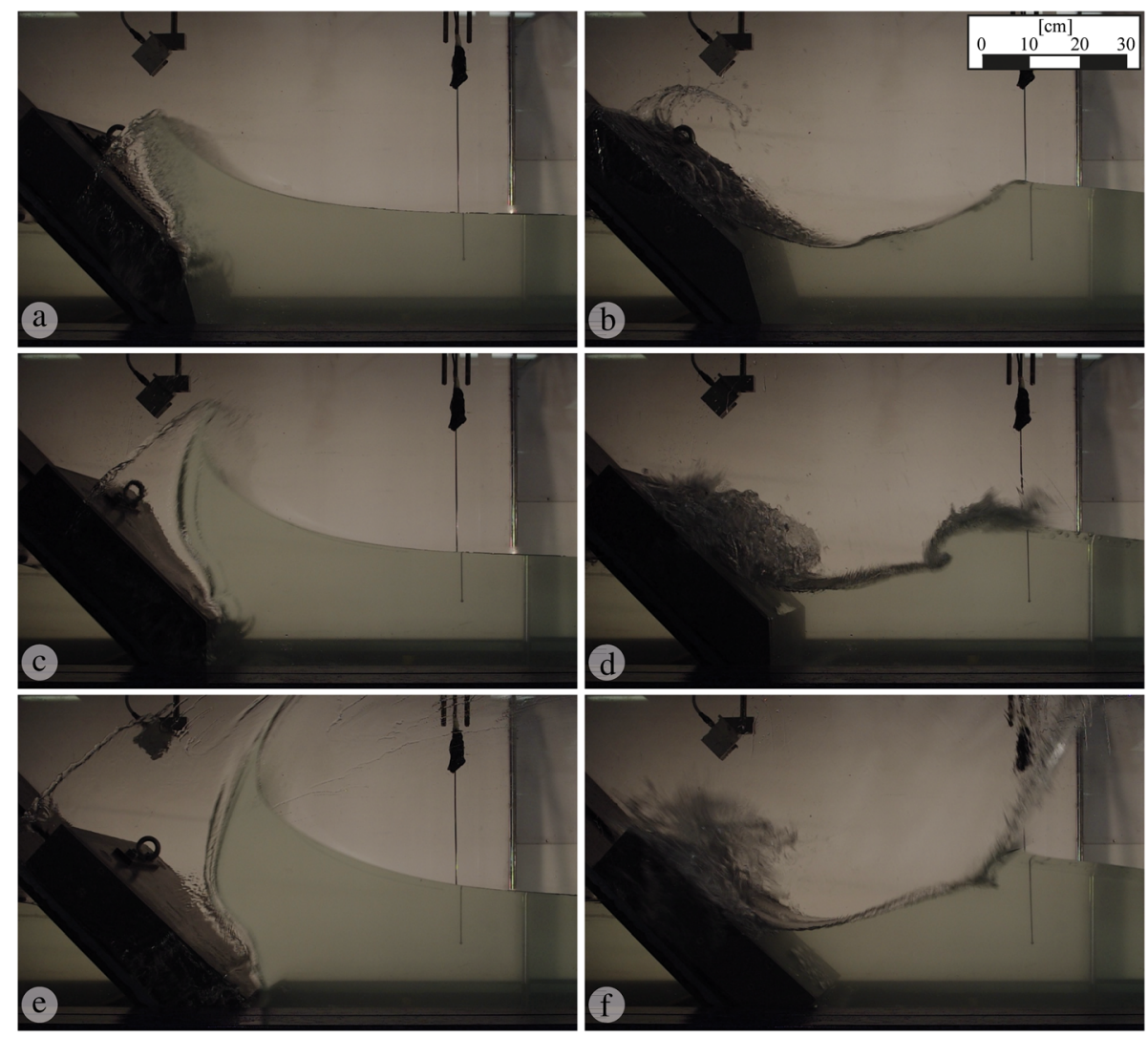

Figure 6. Series of images showing the effect of the slide front angle $\phi$ on wave generation with $h=0.300 \mathrm{~m}, \mathrm{~F} \approx 1.43, S=0.40, M=1.10$, no transition, $b_{\mathrm{s}} / b=0.96$ and $(\mathrm{a}, \mathrm{b}) \phi=30^{\circ}$, (c,d) $\phi=45^{\circ}$, and (e,f) $\phi=90^{\circ}$. 

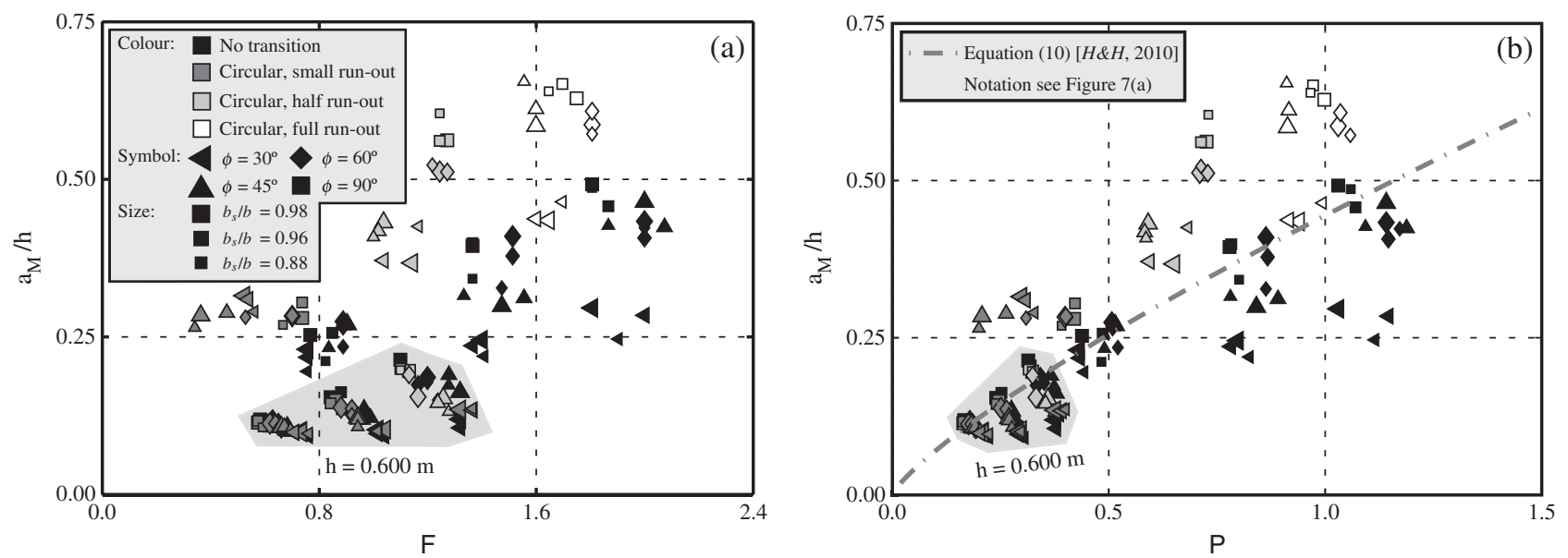

Figure 7. Relative maximum wave amplitude $a_{\mathrm{M}} / h$ versus (a) slide impact Froude number $\mathrm{F}$ and (b) impulse product parameter $P$ for all 144 tests; data marked with a grey background were conducted at $h=0.600 \mathrm{~m}$, and the dashed-dotted line reflects the empirical equation of Heller and Hager [2010] ([H\&H, 2010]) for granular slides.

the effect of the blockage ratio is much less dominant than the effects of $\phi$ and the transition type. Note that the notation of symbols introduced in Figure 7a remains the same throughout the whole article.

[25] Figure 7b shows $a_{\mathrm{M}} / h$ versus the impulse product parameter $\mathrm{P}=\mathrm{F} S^{1 / 2} M^{1 / 4}\{\cos [(6 / 7) \alpha]\}^{1 / 2}$. Also included in Figure $7 \mathrm{~b}$ is the empirical equation for granular tests of Heller and Hager [2010]. Several key features can be observed in Figure 7b: first, the scatter of the data is clearly reduced in Figure $7 \mathrm{~b}$ considering the combined effects of $\mathrm{F}, S, M$, and $\alpha$ in comparison to Figure $7 \mathrm{a}$ where only $\mathrm{F}$ was considered; the parameter $\mathrm{P}$, originally developed for granular slides, also seems to reflect the data of block model tests well. Second, the block slide model data follow a similar trend as the data from granular slides. Third, Figure $7 \mathrm{~b}$ suggests that block slides may generate smaller waves than granular slides, in particularly for the region of small $\mathrm{P}(h=0.600 \mathrm{~m})$. This latter point is in marked contrast to all previous studies, which found that block model slides always generate larger waves than granular slides; this point being discussed in section 4.

[26] Similar plots as shown in Figure $7 \mathrm{~b}$ were produced for the parameters $H_{\mathrm{M}}, T_{\mathrm{M}}, a(x), H(x)$, and $T(x)$, which all showed, after multi variable regression analysis, that $P$ reflects the block model data well. This allows a direct and convenient comparison between the block and the granular slide model data in section 4 . The findings that $\mathrm{P}$ also applies on block model data was previously demonstrated with Figure 1 of Heller and Kinnear [2010], where the block model data of Scelevik et al. [2009] is in good agreement with the empirical equations for granular slides based on $P$.

\subsubsection{Statistical Approach}

[27] To quantify the effects of the three block model parameters (i) to (iii), a statistical approach was applied as shown in Table 3. It considers the isolated effects of each block model parameter (columns) on the wave amplitude $a$ (top), the wave height $H$ (middle), and the wave period $T$ (bottom). For example, the column for the transition type shows the difference $\Delta(\%)$ of a particular wave parameter in a test with circular transition compared to a test without transition, thereby comparing pairs of tests where all remaining test parameters were held constant, as far as possible. These differences $\Delta$ are shown as a mean over all 72 test pairs, for the pair with maximum deviation, and the pair with minimum deviation. For $b_{\mathrm{s}} / b$ and $\phi$ more refined comparisons are possible such that, for example, the fourth column considers all tests with $\phi=90^{\circ}$ relative to the corresponding tests with $\phi=30^{\circ}$

[28] The slide centroid impact velocity $V_{\mathrm{s}}$ may be affected differently for different block model parameters (section 3.1). This is investigated in the third row of Table 3, showing the mean difference $\Delta V_{\mathrm{s}}(\%)$ for the particular test pairs. For example, velocities $V_{\mathrm{s}}$ for tests with a circular transition are in average $10.9 \%$ smaller than for tests without transition, i.e., the transition type indeed systematically affects $V_{\mathrm{s}}$. In order to make a comparison based on one block model parameter only, and holding all remaining test parameters constant, the effect of $\Delta V_{\mathrm{s}}$ is compensated for. This results in the adjusted (subscript adjusted) values shown in Table 3. This correction is achieved with an extrapolation or interpolation, e.g., for the maximum wave amplitude with

$$
a_{\mathrm{M}} / a_{\mathrm{M}, \text { adjusted }}=\left[V_{\mathrm{s}} /\left(V_{\mathrm{s}}-\Delta V_{\mathrm{s}}\right)\right]^{4 / 5}
$$

[29] The following modification of equation (1) can directly be applied to the values in Table 3:

$$
\Delta a_{\mathrm{M}, \text { adjusted }}=\left[\left(1+\Delta a_{\mathrm{M}} / 100\right)\left(1-\Delta V_{\mathrm{s}} / 100\right)^{4 / 5}-1\right] 100 .
$$

[30] The exponents, 4/5 in the example of equation (2), are from the empirical equations of Heller and Hager [2010] describing granular slides. Exponents from a granular slide study were selected because the corresponding exponents for block slides of the present study are unknown at this stage and no other block model study investigated all of the wave parameters addressed in Table 3 . Note that the correction would change insignificantly if it were based on the exponents for block slides, as described at a later stage 
Table 3. Statistical Effect of Three Block Model Parameters on Wave Parameters ${ }^{\mathrm{a}}$

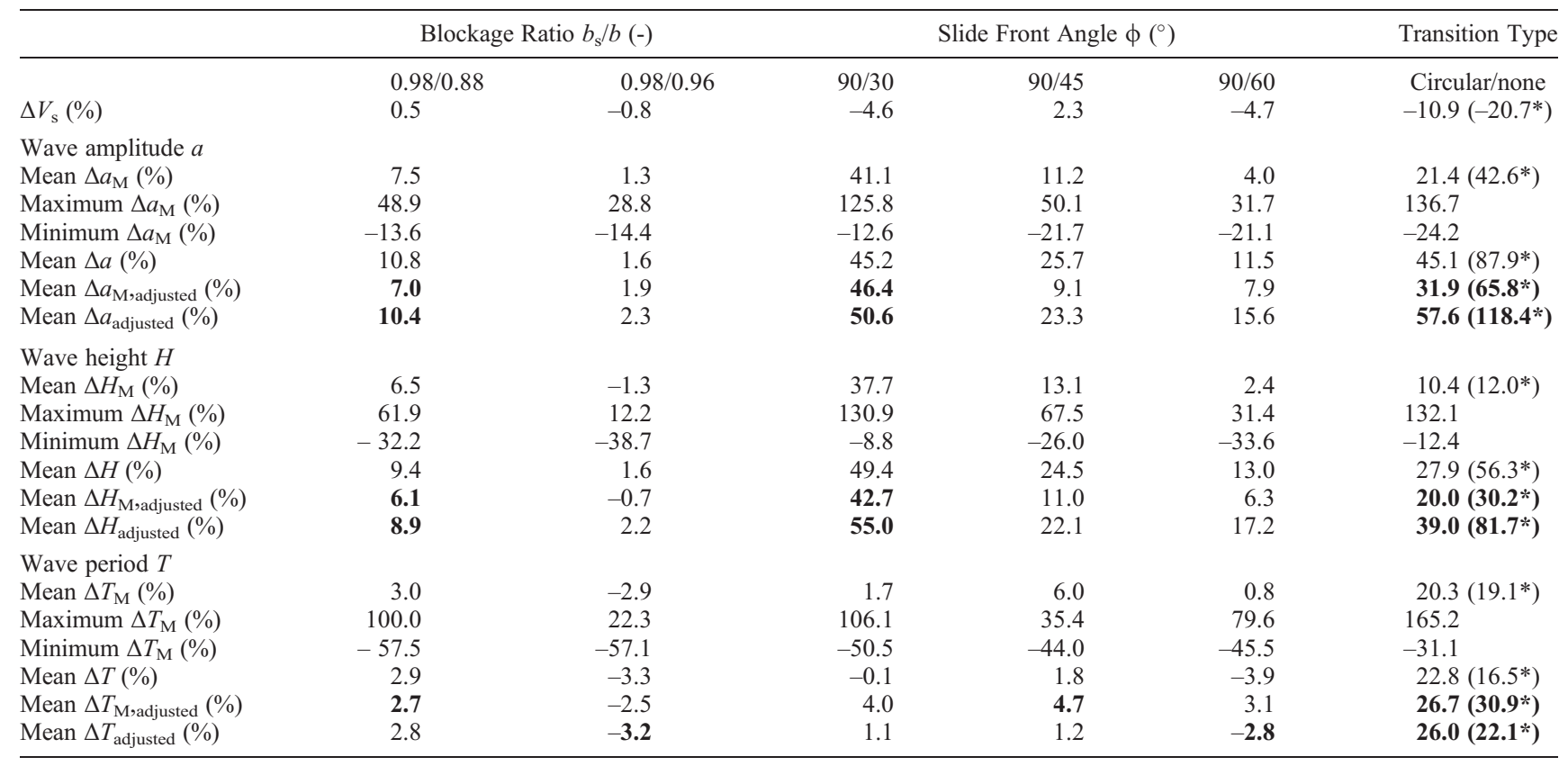

${ }^{a}$ Mean, maximum, and minimum differences $\Delta(\%)$ of a particular wave parameter within test pairs where only one specific block model parameter is different, for wave amplitude a (top), wave height $H$ (middle), and wave period $T$ (bottom); adjusted values are based on corrections compensating for the difference in slide impact velocity $\Delta V_{\mathrm{s}}$.

in this article, because they are generally very close to the exponents of granular slides.

[31] For all tests conducted with a water depth $h=0.300 \mathrm{~m}$, a final parameter changing between test pairs addressing the transition type is the relative slide mass $M=m_{\mathrm{s}} /\left(\rho_{\mathrm{w}} b_{\mathrm{s}} h^{2}\right)$. This is due to the rear part of the slide remaining above the calm water surface for tests without transition (Figure 4d), while it fully submerges for the corresponding tests with circular transition (Figure 4i). This effect could be estimated with the same methodology as shown in the previous paragraph for $V_{\mathrm{s}}$. However, because the effect of $M$ on the wave parameters is relatively small ( $\mathrm{P}$ includes $M$ with an exponent $1 / 4$ in contrast to the slide Froude number with $\mathrm{F}^{1}$ including $V_{\mathrm{s}}$ linearly), it affects the wave parameters for $h=0.300 \mathrm{~m}$ only by about 8 to $16 \%$. This effect was neglected and not compensated for in Table 3.

[32] The numbers in bold in Table 3 show the maximum values for a particular block model and wave parameter. The effect of the transition type is $\Delta a_{\mathrm{M} \text {, adjusted }}=31.9 \%$ in average for $a_{\mathrm{M}}$ and $\Delta a_{\text {adjusted }}=57.6 \%$ for $a(x)$. The values marked with $*$ are based on the 36 test pairs conducted at the smaller water depth $h=0.300 \mathrm{~m}$. The effect of the transition for $h=0.300 \mathrm{~m}$ is larger (e.g., $\Delta a_{\text {adjusted }}=118.4 \%$ ) than for both water depths combined $\left(\Delta a_{\text {adjusted }}=57.6 \%\right)$ because for tests at $h=0.600 \mathrm{~m}$ the primary wave has already propagated away from the slide impact zone once the slide reaches the transition. Besides the transition type, the slide front angle $\phi$ also has a significant effect on the wave amplitude $(50.6 \%)$ and height $(55.0 \%)$. The wave period is an order of magnitude less affected by $\phi$, with $\Delta T_{\text {adjusted }}=-2.8 \%$. Relatively moderate is the effect of the blockage ratio $b_{\mathrm{s}} / b$ on the wave parameters, e.g., $\Delta a_{\text {adjusted }}=10.4 \%$. The values for $a$ and $H$ increase approximately linear with increasing $b_{\mathrm{s}} / b$, while its effect on $T(-3.2 \%)$ may be neglected. However, if this linear effect was extrapolated to $b_{\mathrm{s}} / b=0.526$ used in Walder et al. [2003], it would lead to a discrepancy of approximately $50 \%$. Generally speaking, the effects of $b_{\mathrm{s}} / b$ and $\phi$ on the wave period are not very pronounced for the investigated ranges, such that they are neglected in the empirical equations deduced in section 3.3.

[33] All three block model parameters combined affect $a(x)$ and $H(x)$ by more than a factor of two $(119 \%)$ based on mean values, and exceed a factor of four $(311 \%)$ for not adjusted $a_{\mathrm{M}}$ of individual tests. This demonstrates the importance of considering the effects of the block model parameters in empirical equations.

\subsection{Generic Prediction of Wave Parameters}

[34] Based on the discussion in section 3.2 and a careful analysis of Table 3, a set of nondimensional expressions may be developed as follows. The approximately linear effect of the blockage ratio on the wave amplitude and height can be considered with $B=b_{\mathrm{s}} / b$. The slide front angle may be included with the expression $\Phi=\sin ^{1 / 2} \phi$ resulting in $\sin ^{1 / 2} 90^{\circ} / \sin ^{1 / 2} 30^{\circ}=1.41, \sin ^{1 / 2} 90^{\circ} / \sin ^{1 / 2} 45^{\circ}=1.19$, and $\sin ^{1 / 2} 90^{\circ} / \sin ^{1 / 2} 60^{\circ}=1.07$. This is reasonably close to the values in Table 3, e.g., $\Delta H_{\mathrm{M}}$,adjusted $=42.7 \%$ (1.43) resulting from $90^{\circ} / 30^{\circ}, 11.0 \%$ (1.11) from $90^{\circ} / 45^{\circ}$, and $6.3 \%$ (1.06) from $90^{\circ} / 60^{\circ}$. A more appropriate parameter for wave generation than $\phi$ is the slide front orientation angle $\phi+\alpha$ [Kamphuis and Bowering, 1972; Heller and Kinnear, 2010]. However, because $\alpha=45^{\circ}=$ constant in this study, the effect of $\phi+\alpha$ remains open for future research.

[35] A simple but effective model to consider the significant alteration of the slide kinematics with the transition type is developed hereafter. It is based on the characteristic time of submerged (subscript $\mathrm{s}$ ) landslide motion $t_{\mathrm{s}}$ introduced by Walder et al. [2003]. This characteristic time $t_{\mathrm{s}}$ is defined herein as the submerged horizontal slide travel distance divided by the mean slide velocity. The model includes the 
assumption that the slide on the circular transition stops one slide length $V_{\mathrm{s}} /\left(s b_{\mathrm{s}}\right)$ after the slope toe, and that the mean velocity of the slide from impact to this stop position is $V_{\mathrm{s}}$ such that $t_{\mathrm{s}}=\left[h / \tan \alpha+V_{\mathrm{s}} /\left(s b_{\mathrm{s}}\right)\right] / V_{\mathrm{s}}$ for tests with circular transition and $t_{\mathrm{s}}=(h / \tan \alpha) / V_{\mathrm{s}}$ for tests without transition. Relating $t_{\mathrm{s}}$ of the transition under consideration to the circular transition, and considering that $\alpha=45^{\circ}$, results in the expression $T_{\mathrm{s}}=t_{\mathrm{s}} /\left\{\left[h+V_{\mathrm{s}} /\left(s b_{\mathrm{s}}\right)\right] / V_{\mathrm{s}}\right\}$. Note that $T_{\mathrm{s}}$ is directly and entirely based on a priori estimable slide parameters in real-world cases as well as $h$. This is a key-advantage for real-world predictions. A typical value for tests without transition is $T_{\mathrm{s}}=\left[(h / \tan \alpha) / V_{\mathrm{s}}\right] /\left\{\left[h / \tan \alpha+V_{\mathrm{s}} /\left(s b_{\mathrm{s}}\right)\right] / V_{\mathrm{s}}\right\}=h /\left[h+V_{\mathrm{s}} /\left(s b_{\mathrm{s}}\right)\right]=$ $0.6 /[0.6+0.0373 /(0.12 \cdot 0.588)]=0.53$ and for tests with circular transition $T_{\mathrm{s}}=1$. The ratio circular/none $=1 / 0.53=1.88$ is in reasonable agreement with the values shown in Table 3, e.g., for $\Delta a_{\text {adjusted }}=57.6 \%$ (1.58). The three expressions for the block model parameters are summarized as follows:

(i) Blockage ratio: $B=b_{\mathrm{s}} / b$

(ii) Slide front angle: $\Phi=\sin ^{1 / 2} \phi$

(iii) Transition type: $T_{\mathrm{s}}=t_{\mathrm{s}} /\left\{\left[h+V_{\mathrm{s}} /\left(s b_{\mathrm{s}}\right)\right] / V_{\mathrm{s}}\right\}$

[36] The data in Table 3 allowed the three expressions (i) to (iii) to be developed in their basic form. However, ratios, e.g., the aforementioned 1.88, will change depending on the exponents selected for (i) to (iii). These exponents are found in the following data analysis with the overall criteria to optimize the goodness of fit. The merit of considering the block model parameters with the expressions (i) to (iii) is not only their representation of the mean wave statistics in Table 3, but also their reduction to 1 for granular slides (section 4.1). This feature is highly convenient regarding the comparison of tsunamis generated by block and granular slides (section 4).

[37] Figure 8 shows the final correlations of the relative maximum wave amplitude $a_{\mathrm{M}} / h$ (Figure $8 \mathrm{a}$ ), height $H_{\mathrm{M}} / h$ (Figure $8 \mathrm{~b}$ ), and period $T_{\mathrm{M}}(g / h)^{1 / 2}$ (Figure $8 \mathrm{c}$ ). Figure 8 predicts the wave features in the slide impact zone, which are particularly relevant for narrow reservoirs, lakes, and fjords. The three wave parameters in Figure 8 are shown as a function of the impulse product parameter $\mathrm{P}$ multiplied by a combination of the three expressions $B, \Phi$, and $T_{\mathrm{s}}$. The empirical equations describing the data are

$$
\begin{aligned}
& a_{\mathrm{M}} / h=(3 / 4)\left(\mathrm{P} B \Phi T_{\mathrm{s}}{ }^{1 / 2}\right)^{9 / 10} \quad\left(R^{2}=0.88\right) \\
& H_{\mathrm{M}} / h=\left(\mathrm{P} B \Phi T_{\mathrm{s}}{ }^{1 / 4}\right)^{9 / 10} \quad\left(R^{2}=0.93\right) \\
& T_{\mathrm{M}}(g / h)^{1 / 2}=(19 / 2)\left(\mathrm{P} T_{\mathrm{s}}^{1 / 2}\right)^{1 / 4} \quad \text { for all data }\left(R^{2}=0.24\right) \\
& T_{\mathrm{M}}(g / h)^{1 / 2}=(19 / 2)\left(\mathrm{P} T_{\mathrm{s}}{ }^{1 / 2}\right)^{1 / 7} \text { if observed at primary wave } \\
& \left(R^{2}=0.31\right)
\end{aligned}
$$

[38] Note that the three expressions and their exponents in equations (3) to (5) reflect the mean differences found in Table 3. For instance, $B^{9 / 10}$ in equations (3) and (4) ensure that the effect of the blockage ratio on $a_{\mathrm{M}}$ and $H_{\mathrm{M}}$ is approximately linear, the expression $T_{\mathrm{s}}^{9 / 20}$ for $a_{\mathrm{M}}$ and $T_{\mathrm{s}}^{9 / 40}$ for $H_{\mathrm{M}}$ shows that the transition type has a larger effect on $a_{\mathrm{M}}$ than on $H_{\mathrm{M}}$, or the effects of $B$ and $\Phi$ were neglected for $T_{\mathrm{M}}$ in equation (5). To indicate the amount of scatter involved in Figure 8, lines of $\pm 30 \%$ or $\pm 50 \%$ deviations
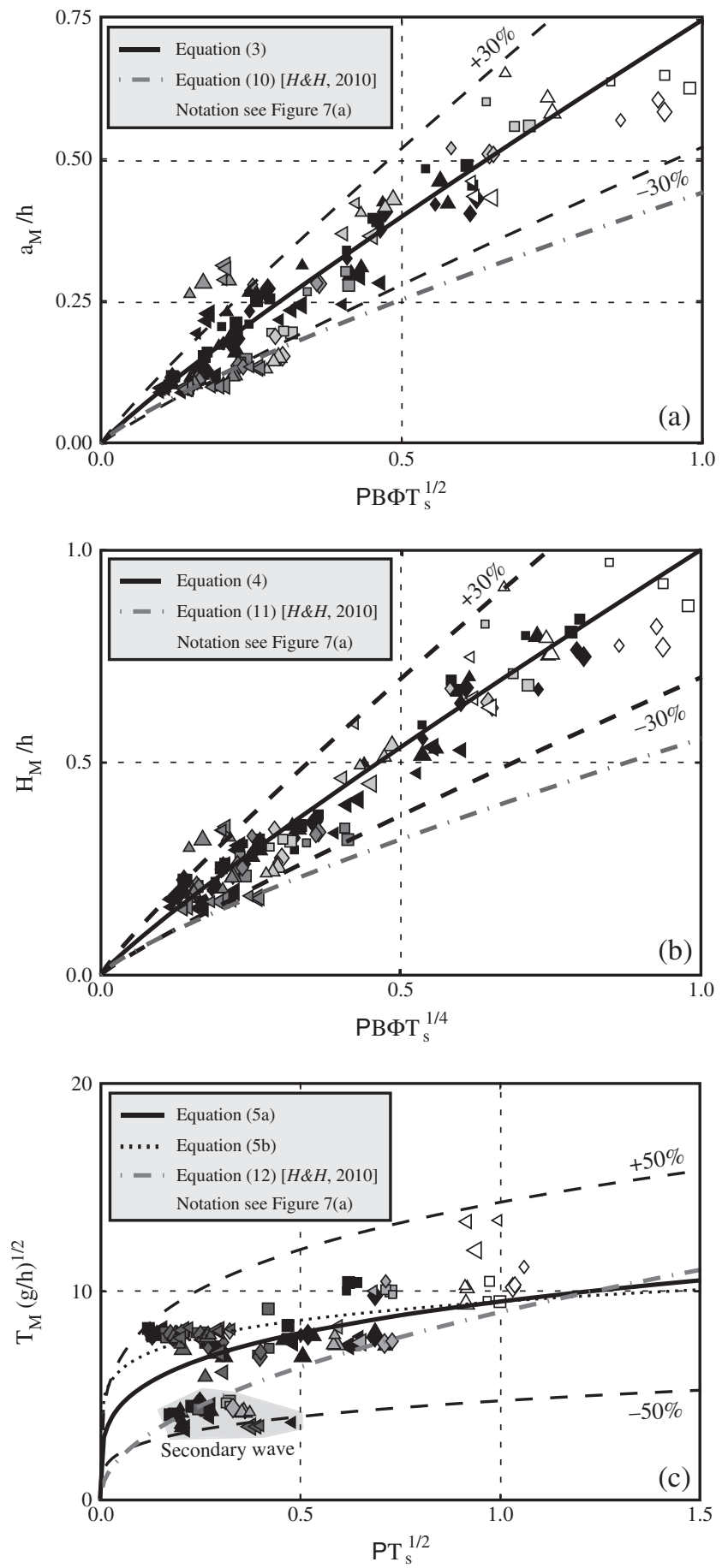

Figure 8. (a) Relative maximum wave amplitude $a_{\mathrm{M}} / h$ versus $\mathrm{P} B \Phi T_{\mathrm{s}}^{1 / 2}$ and equation (3) plotted as (-) with $\pm 30 \%$ deviation as $(--)\left(R^{2}=0.88\right)$, (b) relative maximum wave height $H_{\mathrm{M}} / h$ versus $\mathrm{P} B \Phi T_{\mathrm{s}}^{1 / 4}$ and equation (4) as (-) with $\pm 30 \%$ deviation as $(--)\left(R^{2}=0.93\right)$, and (c) relative maximum wave period $T_{\mathrm{M}}(g / h)^{1 / 2}$ versus $\mathrm{P} T_{\mathrm{s}}^{1 / 2}$ and equations (5a) and (5b) plotted as (-) with $\pm 50 \%$ deviation for the former curve as (--) $\left(R^{2}=0.24\right.$ and $\left.R^{2}=0.31\right) ;[H \& H, 2010]=[$ Heller and Hager, 2010].

are included containing most of the data. The data scatter generally increases with decreasing abscissa value. The coefficients of determination for $a_{\mathrm{M}}\left(R^{2}=0.88\right)$ and $H_{\mathrm{M}}$ 
$\left(R^{2}=0.93\right)$ are excellent, whereas it is only $R^{2}=0.24$ for $T_{\mathrm{M}}$. As is common for subaerial landslide-tsunamis, the wave period is much more challenging to predict than the wave amplitude or height.

[39] Figure 8c shows a gap between data from tests where the primary wave (upper data) includes $a_{\mathrm{M}}$ (and $T_{\mathrm{M}}$ ), and where the secondary wave (lower data) includes $T_{\mathrm{M}}$. Such a clear separation was not observed for the granular tests in Heller and Hager [2010], mainly because $a_{\mathrm{M}}$ was in $95 \%$ of the cases measured at the primary wave. Herein, only for $77 \%$ of the tests the primary wave was the largest, such that $23 \%$ of the data of $T_{\mathrm{M}}$ are based on the shorter secondary wave. To be consistent with the granular tests (section 4), equation (5a) reflects all data. The goodness of fit is slightly improved in equation (5b) describing the data of tests involving the primary wave only; however, this would exclude the sometimes larger secondary wave. Note that the waves were measured in both the near field (splash zone) and far field. Measurements in the splash zone are important when looking at narrow reservoirs, lakes, or fjords; however, such measurements increase the overall data scatter.

[40] Figures 9 and 10 show the evolution of the wave parameters with relative distance $X=x / h$ to predict the wave features in the wave propagation zone. Shown are the relative wave amplitude $a(x) / h$ (Figure 9a), height $H(x) / h$ (Figure 9b), and period $T(x)(g / h)^{1 / 2}$ (Figure 10). Because $X$ is included with a negative exponent in Figure 9, the origin corresponds to $X \rightarrow \infty$ where both $a(x)$ and $H(x)$ reduce to zero. In contrast, the wave period $T(x)$ in Figure 10 increases with distance. The humps of landslide-tsunamis may consist of a dispersive wave package and the increase in $T(x)$ is mainly due to amplitude and frequency dispersion. The following power laws describe the data in Figures 9 and 10:

$$
\begin{gathered}
a(x) / h=(11 / 10)\left(\mathrm{P} X^{-1 / 3} B \Phi T_{\mathrm{s}}{ }^{3 / 4}\right)^{9 / 10} \quad\left(R^{2}=0.85\right) \\
H(x) / h=(3 / 2)\left(\mathrm{P} X^{-1 / 3} B \Phi T_{\mathrm{s}}{ }^{1 / 2}\right)^{9 / 10} \quad\left(R^{2}=0.89\right) \\
T(x)(g / h)^{1 / 2}=(13 / 2)\left(\mathrm{P} X^{5 / 4} T_{\mathrm{s}}{ }^{1 / 3}\right)^{1 / 4} \quad \text { for all data }\left(R^{2}=0.53\right)
\end{gathered}
$$

$T(x)(g / h)^{1 / 2}=(33 / 4)\left(\mathrm{P} X^{5 / 4} T_{\mathrm{s}}{ }^{1 / 3}\right)^{2 / 9}$ if observed at primary wave $\left(R^{2}=0.80\right)$

[41] The coefficients of determination $R^{2}$ are excellent for $a(x)$ and $H(x)$, and lines of $\pm 30 \%$ and $\pm 50 \%$ deviations illustrate again the amount of data scatter in Figures 9 and 10.

[42] The effects of the expressions $B$ (considering the blockage ratio) and $\Phi$ (considering the slide front angle) on $T$ are again neglected. The wave period mainly depends on the characteristic time $t_{\mathrm{s}}$ of submerged landslide motion rather than its width or front shape. The transition type included with $T_{\mathrm{s}}$ and exponent $1 / 12$ in equation (8a) therefore affects $T$. The separation of the data in Figure 10 from the primary and secondary wave is even more obvious than in Figure 8c.

[43] The wave celerity $c$ indicates the available time to react to a tsunami after wave generation at a specific distance from the source. Furthermore, and perhaps more important, $c$ also helps to estimate the wavelength $L$, e.g., with the regular wave expression $L=T c$. The parameter $L$ is relevant in determining the effects of impulse waves on a shore or
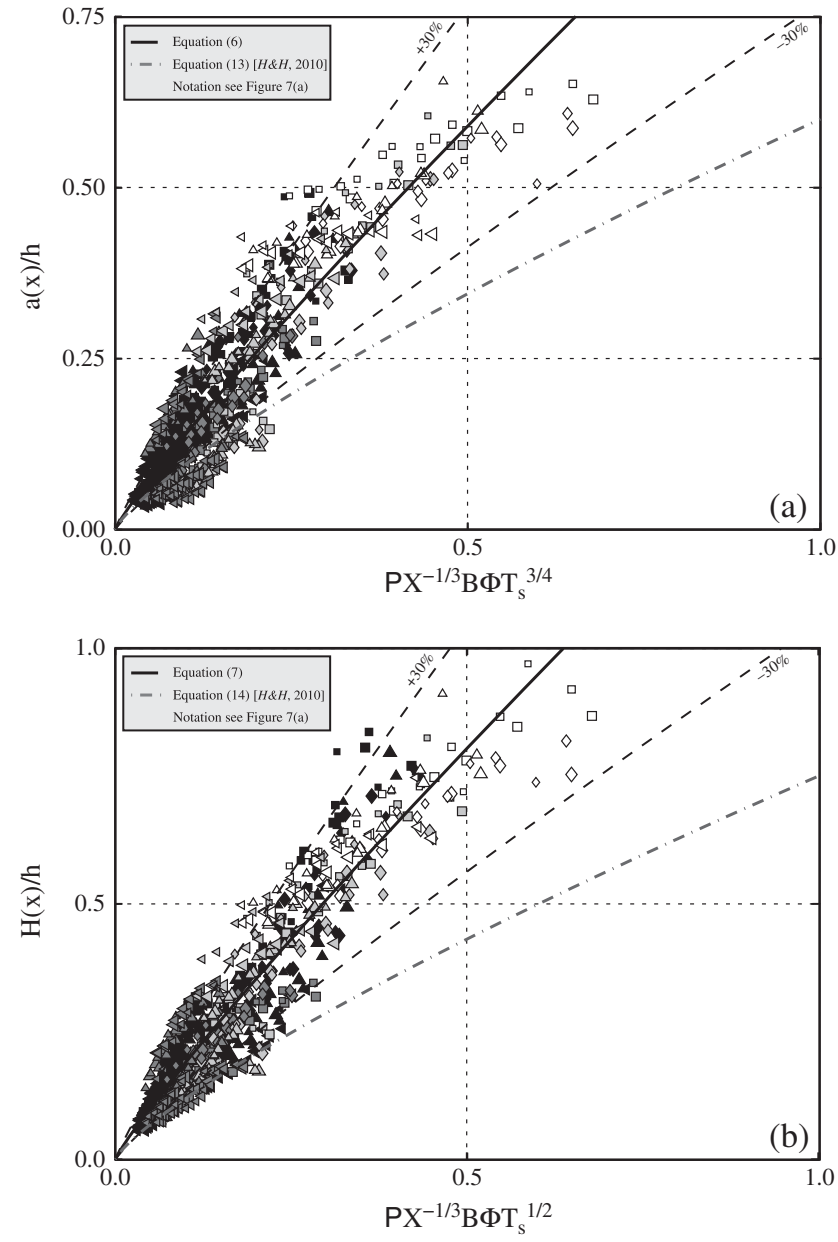

Figure 9. (a) Relative wave amplitude $a(x) / h$ versus $\mathrm{P} X^{-1 / 3} B \Phi T_{\mathrm{s}}^{3 / 4}$ and equation (6) plotted as (-) with $\pm 30 \%$ deviation as (--) $\left(R^{2}=0.85\right)$ and (b) relative wave height $H(x) / h$ versus $\mathrm{P} X^{-1 / 3} B \Phi T_{\mathrm{s}}^{1 / 2}$ and equation (7) as (-) with $\pm 30 \%$ deviation as $(--)\left(R^{2}=0.89\right)$; $[H \& H, 2010]=$ [Heller and Hager, 2010].

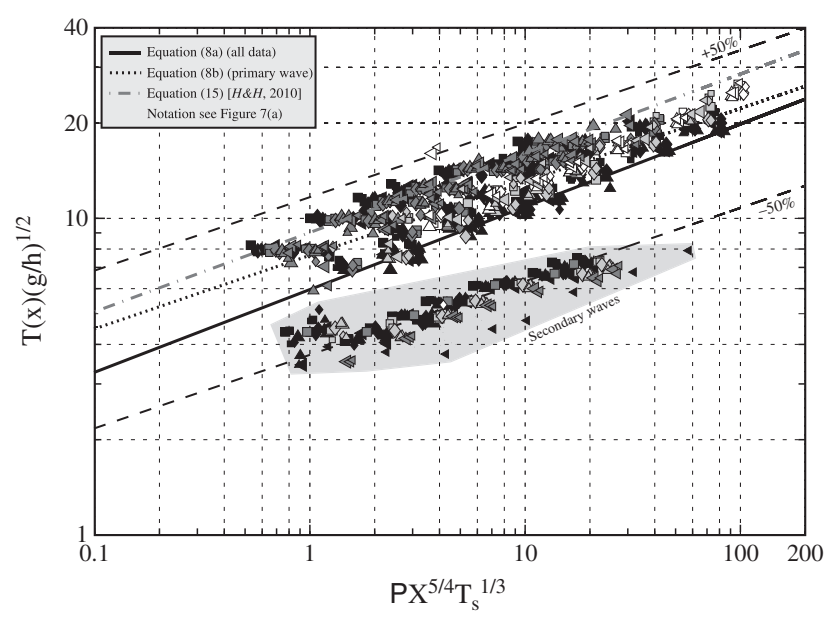

Figure 10. Relative wave period $T(x)(g / h)^{1 / 2}$ versus $\mathrm{P} X^{5 / 4} T_{\mathrm{s}}^{1 / 3}$ and equations (8a) and (8b) plotted as (-) with $\pm 50 \%$ deviation for the upper curve as (--) $\left(R^{2}=0.53\right.$ and $\left.R^{2}=0.80\right) ;[H \& H, 2010]=$ [Heller and Hager, 2010]. 
dam [Müller, 1995]. Figure 11 shows the relative wave celerity $c /(g h)^{1 / 2}$ as a function of the relative mean (subscript $\mathrm{m}$ ) wave amplitude $a_{\mathrm{m}} / h$ of two subsequent wave probes. The celerity $c$ was derived with the distance between two subsequent wave probes divided by the travel time of the wave hump center resulting in six values for each experiment. In similarity to Kamphuis and Bowering [1972], the data in Figure 11 are compared with the solitary wave speed given by Boussinesq [1872] as

$$
c /(g h)^{1 / 2}=1+a_{\mathrm{m}} /(2 h)
$$

[44] The data are slightly lower than equation (9) supporting that landslide-tsunamis consist of a wave package propagating with a group celerity rather than a phase celerity as given by equation (9), where the group celerity is commonly smaller than the phase celerity. The separation between primary and secondary wave is also obvious in Figure 11.

[45] The herein investigated landslide-tsunamis can now be characterized with the presented data. The wave length $L=c / T$ can be computed with $T$ from Figure 10 and $c$ from Figure 11. The relative wave length is in the range $2.1 \leq L / h \leq 31.9$, which is characteristic for intermediate- to shallow-water waves. The wave nonlinearity can be defined with the Ursell parameter $\mathrm{U}=(H / L)(h / L)^{3}=H L^{2} / h^{3}$, with $\mathrm{U} \rightarrow$ 0 for linear waves [Panizzo et al., 2005b; Ursell, 1953; Heller and Hager, 2011]. The range of the investigated waves is $0.7 \leq \mathrm{U} \leq 605.6$. The generated landslide-tsunamis may therefore be characterized as moderate to highly nonlinear in the intermediate- to shallow-water regime. This is typical for subaerial landslide-tsunamis [Fritz et al., 2004; Panizzo et al., 2005b; Heller and Hager, 2011].

\section{Comparison of Tsunamis Generated by Block and Granular Slides}

\subsection{Base of Comparison}

[46] To compare landslide-tsunamis generated by block and granular slides, an appropriate base of comparison has to be defined. In this context, the parameters in a block slide test must be correlated to the conditions in a granular slide

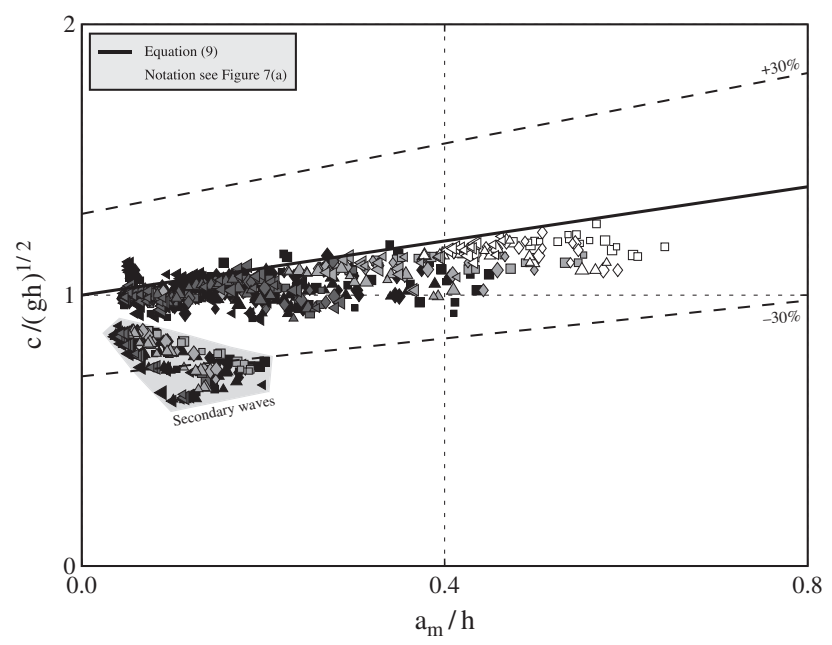

Figure 11. Relative hump center wave celerity $c /(g h)^{1 / 2}$ versus mean relative amplitude $a_{\mathrm{m}} / h$ and solitary wave speed (equation (9)) plotted as (-) with $\pm 30 \%$ deviation as (--). test. Both block and granular slide tests should be based on identical dimensionless parameters $\mathrm{F}, S, M$, and $\alpha$, and the wave characteristics should be compared at the identical location $x / h$. Furthermore, a granular slide fills the whole channel width such that $b_{\mathrm{s}} / b=1$ applies; this being best represented by the blockage ratio $b_{\mathrm{s}} / b=0.98$ of the present study.

[47] It remains an open question as to which the four investigated slide front angles $\phi$ and two transition types are representative for granular slide tests. It may be argued that a subaerial granular slide for the investigated Froude number range $F \geq 0.34$ deforms during impact, such that $\phi$ approximates $90^{\circ}$. This is due to the slide nose front being more decelerated for $\phi<90^{\circ}$ than the remaining part of the nose. The angle $\phi$ was indeed never included in granular slide studies, and this omission may be explained with the argument that $\phi$ adapts to approximately $90^{\circ}$ for all granular slides. The deformation of the front nose can be observed in Figure 3b of Heller and Hager [2010] and in Figures 5a and $5 \mathrm{~b}$ of Heller and Hager [2011]. The assumption $\phi \approx 90^{\circ}$ for granular slides must be understood as a rough estimation. Nevertheless, it seems more appropriate than the comparison to one of the remaining three angles $\phi=30^{\circ}, 45^{\circ}, 60^{\circ}$.

[48] The published literature shows further that granular slides run out quite smoothly despite an abrupt transition at the slope toe. This is in close similarity to the block slide for a circular transition; examples being given by Fritz et al. [2004] (Figure 1) and Heller and Hager [2010] (Figure 3). Therefore, a block slide with $b_{\mathrm{s}} / b=0.98(B \approx 1), \phi=90^{\circ}$ $(\Phi=1)$, a circular transition $\left(T_{\mathrm{s}}=1\right)$, and identical parameters $\mathrm{F}, S, M, \alpha$, and $X$ is selected as a base for the most direct comparison between tsunamis generated by block and granular slides.

\subsection{Quantification of the Effect of the Slide Model}

[49] In addition to the functions describing the new block model tests, Figures 8, 9, and 10 also include the equations reflecting granular slide tests from Heller and Hager [2010]. Their study is based on 434 tests with slide Froude number $0.86 \leq \mathrm{F} \leq 6.83$, relative slide thickness $0.09 \leq S \leq 1.64$, relative slide mass $0.11 \leq M \leq 10.02$, hill slope angle $30^{\circ} \leq \alpha \leq 90^{\circ}$, impulse product parameter $0.17 \leq \mathrm{P} \leq 8.13$, and relative distance $0.0 \leq x / h \leq 59.0$. Given that for granular slides $B=\Phi=T_{\mathrm{s}}=1$ (section 4.1), the inclusion of these block model parameters on the $x$ axis does not affect the equations of Heller and Hager [2010] in their original form (with $R^{2}$ relative to their granular slide tests)

$$
\begin{array}{cc}
a_{\mathrm{M}} / h=(4 / 9) \mathrm{P}^{4 / 5} & \left(R^{2}=0.88\right) \\
H_{\mathrm{M}} / h=(5 / 9) \mathrm{P}^{4 / 5} & \left(R^{2}=0.82\right) \\
T_{\mathrm{M}}(g / h)^{1 / 2}=9 \mathrm{P}^{1 / 2} & \left(R^{2}=0.33\right) \\
a(x) / h=(3 / 5)\left(\mathrm{P} X^{-1 / 3}\right)^{4 / 5} & \left(R^{2}=0.81\right) \\
H(x) / h=(3 / 4)\left(\mathrm{P} X^{-1 / 3}\right)^{4 / 5} & \left(R^{2}=0.80\right) \\
T(x)(g / h)^{1 / 2}=9\left(\mathrm{P} X^{5 / 4}\right)^{1 / 4} & \left(R^{2}=0.66\right) .
\end{array}
$$

[50] Figures 8 and 9 show that the functions reflecting block slides (equations (3), (4), (6), and (7)) always predict larger waves than the functions reflecting granular slides 


\section{HELLER AND SPINNEKEN: IMPROVED LANDSLIDE-TSUNAMI PREDICTION}

(equations (10), (11), (13), and (14)). This comparison is based on the assumption that the three block model parameters are not considered. Equations (5a) and (12) for the maximum wave period $T_{\mathrm{M}}(g / h)^{1 / 2}$ intersect at $\mathrm{P} T_{\mathrm{s}}^{1 / 2}=1.24$ in Figure $8 \mathrm{c}$, while equation (8a) for the wave period evolution $T(x)(g / h)^{1 / 2}$ for block slides is above equation (15) for granular slides (Figure 10). The same observation was made by Ataie-Ashtiani and Nik-Khah [2008] who noted that granular slides generate up to $30 \%$ longer waves than block slides. The two functions for each parameter in Figures 8, 9, and 10 enable a first comparison between waves generated by block and granular slides. Further explanations are required before a more comprehensive comparison is possible.

[51] Figure 12 shows a direct comparison of wave parameters found through block and granular slides. Each subplot includes one of the six analyzed wave parameters. For example, Figure 12a includes functions based on [equation (3)]/[equation (10)] resulting in $a_{\mathrm{M} \text {,block }} / a_{\mathrm{M} \text {, granular }}=$
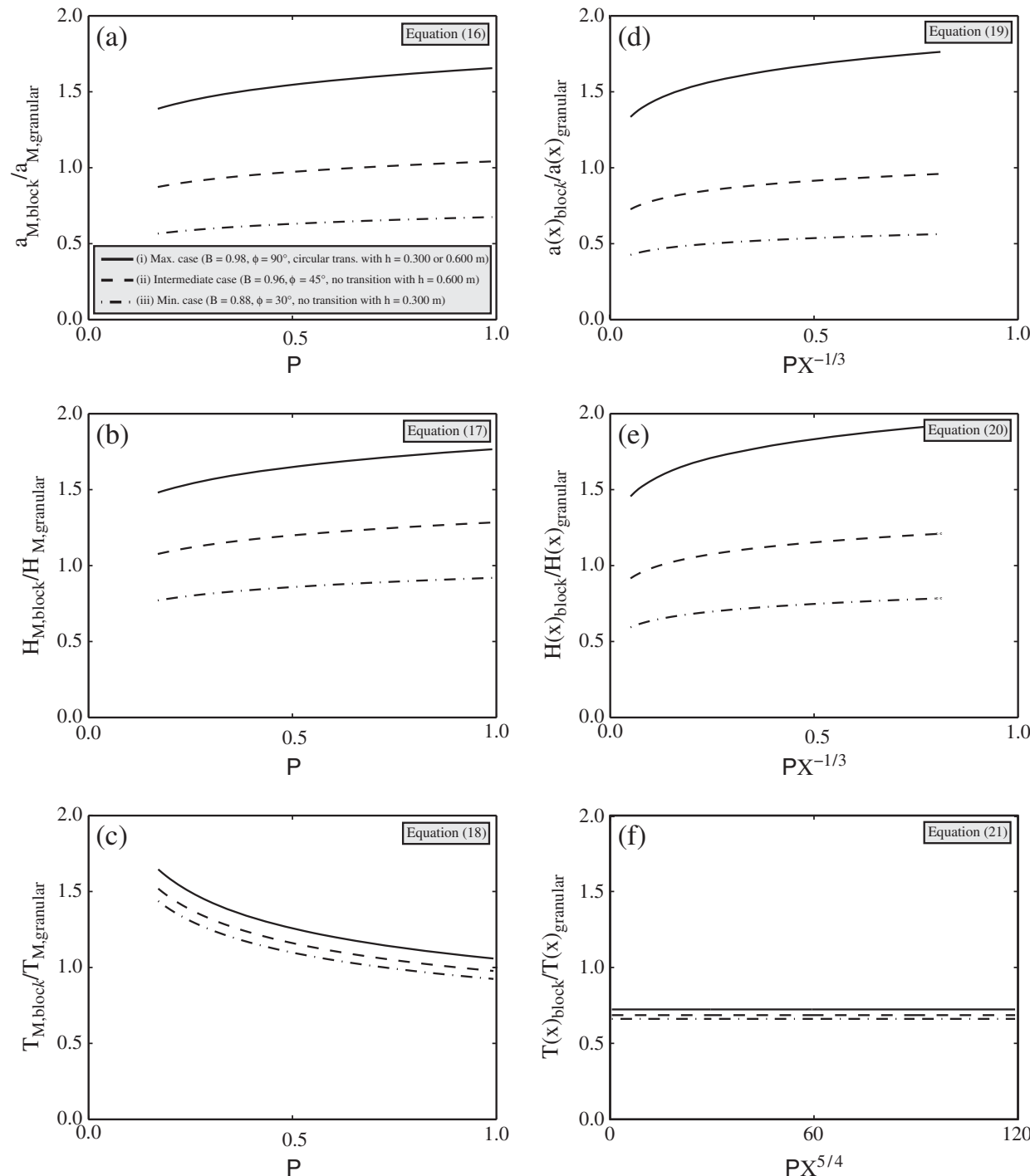

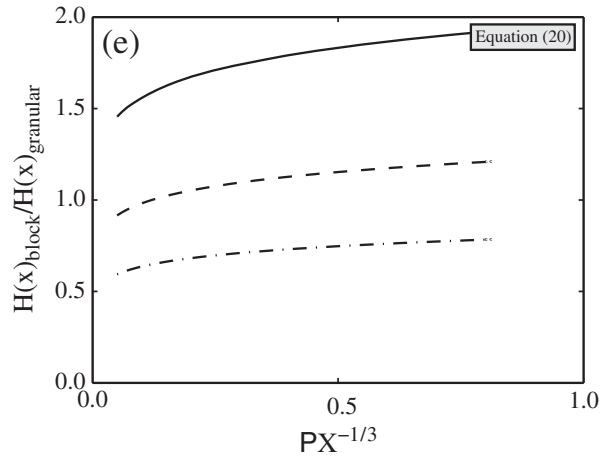

$\left[(3 / 4)\left(\mathrm{P} B \Phi T_{\mathrm{s}}^{1 / 2}\right)^{9 / 10}\right] /\left[(4 / 9) \mathrm{P}^{4 / 5}\right]$. The corresponding functions for all six wave parameters are

$$
\begin{gathered}
a_{\mathrm{M}, \text { block }} / a_{\mathrm{M}, \text { granular }}=(27 / 16) \mathrm{P}^{1 / 10}\left(B \Phi T_{\mathrm{s}}{ }^{1 / 2}\right)^{9 / 10} \\
H_{\mathrm{M}, \text { block }} / H_{\mathrm{M}, \text { granular }}=(9 / 5) \mathrm{P}^{1 / 10}\left(B \Phi T_{\mathrm{s}}{ }^{1 / 4}\right)^{9 / 10} \\
T_{\mathrm{M}, \text { block }} / T_{\mathrm{M}, \text { granular }}=(19 / 18) \mathrm{P}^{-1 / 4} T_{\mathrm{s}}{ }^{1 / 8} \\
a(x)_{\text {block }} / a(x)_{\text {granular }}=(11 / 6) \mathrm{P}^{1 / 10} X^{-1 / 30}\left(B \Phi T_{\mathrm{s}}{ }^{3 / 4}\right)^{9 / 10} \\
H(x)_{\text {block }} / H(x)_{\text {granular }}=2 \mathrm{P}^{1 / 10} X^{-1 / 30}\left(B \Phi T_{\mathrm{s}}{ }^{1 / 2}\right)^{9 / 10}
\end{gathered}
$$

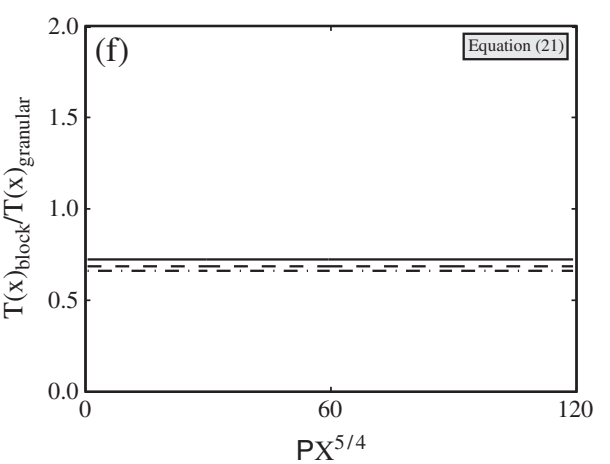

Figure 12. Comparison of waves generated by block and granular slides based on equations (16) to (21)

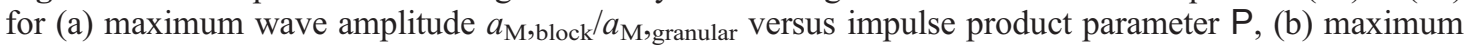

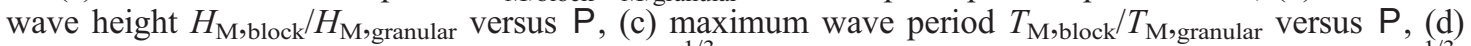

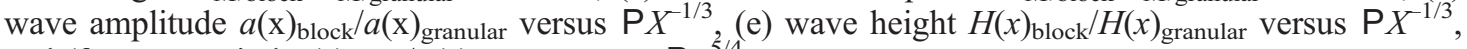
and (f) wave period $T(x)_{\text {block }} / T(x)_{\text {granular }}$ versus $\mathrm{P} X^{5 / 4}$. 


$$
T(x)_{\text {block }} / T(x)_{\text {granular }}=(13 / 18) T_{\mathrm{s}}^{1 / 12} .
$$

[52] Note, to be consistent with the granular tests, equations (5a) and (8a) describing the periods for all data were used to deduce equations (18) and (21), respectively. Equations (16), (17), (19), and (20) show that the ratios slightly increase with $P$ and $F$. Exceptions are equation (18), where the opposite trend is observed, and equation (21) changing only as a function of $T_{\mathrm{s}}$.

[53] All ratios in equations (16) to (21) change as a function of $B, \Phi$, and/or $T_{\mathrm{s}}$. To visualize this, each subplot in Figure 12 includes three curves that lie within the investigated parameter ranges: (i) the maximum ratio $\left(B=0.98, \Phi=1\left(\phi=90^{\circ}\right)\right.$, and $T_{\mathrm{s}}=1$ (circular transition)), (ii) an intermediate case $\left(B=0.96, \Phi=0.84\left(\phi=45^{\circ}\right)\right.$, and $T_{\mathrm{s}}=0.53$ (no transition and $h=0.600 \mathrm{~m})$ ), and (iii) the minimum ratio $(B=0.88, \Phi=0.71$ $\left(\phi=30^{\circ}\right)$, and $T_{\mathrm{s}}=0.34$ (no transition and $\left.h=0.300 \mathrm{~m}\right)$ ). The upmost curve of each subplot describes the most direct comparison since all parameters between block and granulate are identical (section 4.1). However, lower values for $B<0.98, \Phi<1$, and/or $T_{\mathrm{s}}<1$ have also to be compared with the unique set of granular slides $\left(B=\Phi=T_{\mathrm{S}}=1\right)$.

[54] The functions relating to granular slides in Figures 8, 9 , and 10 are generally lower than the corresponding block slide functions. In contrast, the ratios shown in Figure 12 can be significantly lower than 1; the explanation for this being as follows: only the upmost curve in each subplot reflects the ratio of the two particular functions without any change in abscissa value. For the intermediate and minimum ratios, (ii) and (iii) above, an adjustment must be made to reflect the influence of $B, \Phi$, and $T_{\mathrm{s}}$ on the abscissa.

[55] The evidence that follows support the result that block slides can generate smaller waves than granular slides, despite most previous studies finding the opposite trend [cf. Heller and Kinnear, 2010]. First, a granular slide runs out despite the absence of any transition and transfers more momentum to the water than a block slide which abruptly comes to rest. Furthermore, the granular slide nose with angle $\phi<90^{\circ}$ deforms during impact such that $\phi$ approximates $90^{\circ}$ (section 4.1) while a small angle $\phi$ for a block slide remains constant. Both reasons result in a significant reduction of the ratios such that for example $a_{\mathrm{M} \text {,block }} / a_{\mathrm{M} \text {,granular }}=1.66$ reduces to a minimum of 0.57 (Figure 12a). All ratios relating to the wave period $T(x)$ in Figure $12 \mathrm{f}$ are less than one, implying that block slides generate shorter waves than granular slides. This finding is in agreement with Ataie-Ashtiani and Nik-Khah [2008]. A plausible explanation may be that granular slides tend to run-out further than block slides, resulting in the generation of longer waves.

[56] The conclusion that block slides can generate smaller waves than granular slides is in marked contrast to all previous studies that found that block slides always generate larger waves [cf. Heller and Kinnear, 2010]. This discrepancy may be explained by the fact that the three block model parameters remained unconsidered in previous studies. The most comprehensive study investigating the differences between waves generated by block and granular slides is Zweifel [2004], including 11 block model tests and 86 granular tests (section 1.2). The blockage ratio of the block slide in Zweifel's study was $B=0.98$, the slide front angle $\phi=90^{\circ}$, and no transition (and no stopper) was used (Table 1). These conditions are close to the parameters for the upmost curve in Figure $12 \mathrm{a}$, which shows, in agreement with the findings in Zweifel [2004], a ratio $>1$. The present study, however, observes much smaller amplifications, with a maximum of $a_{\mathrm{M} \text {,block }} / a_{\mathrm{M} \text {,granular }}=1.66$, than Zweifel [2004] who found variations of up to a factor of 7.4. A final difference to the findings of Zweifel [2004] is that the ratio in equation (16) increases with $F^{1 / 10}$, whereas Zweifel [2004] found the ratio to decrease with increasing $F$. Other block model parameter combinations, representing the lower curves in Figure 12a, where not investigated by Zweifel [2004].

[57] No other values (apart from $a_{\mathrm{M} \text {,block }} / a_{\mathrm{M} \text {, granular }}$ ) are available from previous studies, except for the findings of Ataie-Ashtiani and Nik-Khah [2008] that block slides generate 20 to $30 \%$ smaller $T_{\mathrm{M}}$ than granular slides. This qualitatively agrees with Figure $12 \mathrm{c}$, however, a direct comparison of the data of Ataie-Ashtiani and Nik-Khah [2008] with the present 2-D data is difficult because their water body geometry was somewhere between 2-D and 3-D. For the same reason, their findings that granular slides generate up to $35 \%$ smaller wave amplitudes than block slides ( $a_{\text {M,block }} /$ $\left.a_{\mathrm{M} \text {,granular }}=1 / 0.65=1.54\right)$ is not investigated in detail herein. However, an approximate comparison shows that 1.54 may agree well with the values predicted by the upmost curve in Figure 12a.

\subsection{Application to Real-World Cases}

[58] Appendix B shows by means of an example, how the present results resolve discrepancies between different model studies. The purpose of this section is to address some important aspects relating to real-world applications of the results. The main focuses of the present study lie on reservoirs, lakes, and fjords where empirical equations are relatively frequently applied. The present results may still be applicable for volcanic islands. In this latter case, the parameters observed may reflect the investigated parameter ranges less well, this being due to larger water depths or smaller hill slope angles.

[59] Tsunamis generated in a wave flume (2-D) and a wave basin (3-D) can be quite different (appendix A). The findings of the present study are based on a 2-D geometry. Even though such narrow geometries can reflect real-world cases (e.g., narrow reservoirs, lakes, or fjords), the wave propagation is more commonly of 3-D nature. Transformation methodologies of results from 2-D to 3-D were presented by Huber and Hager [1997] and Heller et al. [2009, 2012] and also forms part of an on-going research project. The ratios shown in Figure 12 may only be used as a first approximation for 3-D cases because the relation of block to granular slides in $3-\mathrm{D}$ is likely to be different due to the additional deformation of the 3-D granular slide in the lateral direction.

[60] The mass movement types fall and toppling [Cruden and Varnes, 1996] may be best described by the idealized block slide while the remaining types slide, flow, and spread may be better approximated with the idealized granular slide. However, the degree of fragmentation may depend on many additional factors such as subaerial travel distance or the initial tensile strength. The slide type that best reflects a particular real-world case is therefore highly case specific.

[61] The slide kinematics in the present experiments are well represented by the slide centroid impact velocity $V_{\mathrm{s}}$ and the expression $T_{\mathrm{s}}$ for the transition type, as evident by 
the relatively small data scatter in Figures 8 to 10 . A number of experimental effects may result in different slide run-out distances compared to real-world cases. This includes a scale effect due to the overestimated slide friction in the present Froude model, a hill slope angle larger or smaller than $\alpha=45^{\circ}$, an inclined bottom (in contrast to the horizontal channel bottom applied herein), or an impact of the slide on the opposite slope of the valley. This is likely to affect the wave features, at least in the cases where the tsunami has not already left the slide impact zone before the slide comes to rest. The magnitude of this effect and how it would alter $T_{\mathrm{s}}$ remain open questions for future research.

[62] An abrupt slide stop at the slope toe is rather unlikely in a real-world case. Nevertheless, in some physical model studies, the slide was modeled in this fashion (Table 1). The present study illustrates the impact of such small model details on the wave features. As a result, any prototype study must carefully adjust these details to the real-world situation.

\section{Conclusions}

[63] The principal aim of this study is to improve hazard assessment of subaerial landslide-tsunamis based on empirical equations with a main focus on reservoirs, lakes, and fjords. To achieve this, 144 wave flume tests were conducted under systematic variation of the slide Froude number $F$, the relative slide thickness $S$, and the relative slide mass $M$. The analyzed wave parameters include the maximum wave amplitude $a_{\mathrm{M}}$, height $H_{\mathrm{M}}$, and period $T_{\mathrm{M}}$ and the wave amplitude $a(x)$, height $H(x)$, and period $T(x)$ evolution with distance $\mathrm{x}$.

[64] Two major shortcomings were resolved: (a) the effect of three important block model parameters and (b) the effect of the slide model (rigid block versus granular slide). To understand (a), (i) the blockage ratio (slide width relative to channel width), (ii) the slide front angle, and (iii) the transition type (no transition with stopper and circular transition) were varied. The effect of (i) was found to be relatively small. However, parameter (ii) changes the wave amplitudes $a(x)$ by up to $50.6 \%$ and the wave heights $H(x)$ by up to $55.0 \%$, as an average over all tests, while its effect upon the wave period $T(x)$ may be neglected. The effect of (iii) is significant for all six investigated wave parameters changing $a(x)$ by up to $57.6 \%, H(x)$ by up to $39.0 \%$, and $T(x)$ by up to $26.0 \%$. All three block model parameters combined change the wave amplitude and height by up to about a factor of two (119\%).

[65] Three nondimensional expressions $B, \Phi$, and $T_{\mathrm{s}}$ were deduced to include the three block model parameters in generic empirical equations. These new empirical equations express the six investigated wave parameters as a simple function of $B, \Phi, T_{\mathrm{s}}$, the impulse product parameter $\mathrm{P}$, and the relative distance $X$. The remaining data scatter (typically $\pm 30 \%$ ) associated with the empirical equations is remarkably small for most wave parameters.

[66] To investigate the effect of the slide model, the newly developed empirical equations for block slides are related to the corresponding empirical equations of Heller and Hager [2010] for granular slides. The resulting Figure 12 shows that block slides in wave channels can generate larger, identical, or even smaller waves than granular slides, depending on which values for the expressions $B, \Phi$, and $T_{\mathrm{s}}$ are selected. For example, the ratio for the wave amplitude is in the range $a_{\text {block}} / a_{\text {granular }}=0.43$ to 1.76 . In contrast, all previous studies found that block slides always generate larger wave amplitudes than granular slides. Surprisingly, this does not contradict the findings of the present work given that previous studies were not varying $B, \Phi$, and/or $T_{\mathrm{s}}$ and they conducted tests in parameter ranges where the block slides of the present study generate larger waves than granular slides as well. A disagreement between this and the study of Zweifel [2004] concerns the maximum observed wave amplitude ratio $a_{\mathrm{M} \text {,block }} / a_{\mathrm{M}, \text { granular }}=1.66$, compared to 7.4 in Zweifel [2004]. The reason for this large discrepancy remains unclear. In contrast, the present results for both the wave amplitude and period agree much better with the findings of Ataie-Ashtiani and Nik-Khah [2008].

[67] The application of the present 2-D results to real-world cases was also addressed. The present results further resolve the question as to why studies based on block slides can predict smaller waves than granular slide studies (appendix B). This knowledge helps to reduce discrepancies between different studies (appendix A) and supports real-world predictions.

\section{Appendix A: Reasons for Discrepancies Between Studies}

[68] Figure A1 shows potential reasons for discrepancies in wave parameter predictions based on different studies. These combined effects may be responsible for deviations of up to a factor of 60 (section 1.1) or even more. The main categories in Figure A1 are model, measurement, and scale effects. Additional discrepancies can be caused by human error, including the calibration of a measurement sensor, an incorrect application of a measurement system, incorrect data analysis or correlation, an erroneous application of the empirical equation, or a typo. The values in square brackets in Figure A1 specify the estimated quantitative effects, expressed as a factor applied on a reference wave amplitude $a$.

[69] The most significant model effect is the water body geometry. Generic physical model studies are conducted in wave flumes (2-D) or wave basins (3-D). The difference in the 2-D and 3-D wave amplitude in the slide impact zone is relatively small, whereas it increases with increasing propagation distance, resulting in deviations of up to an order of magnitude or even more [Heller et al., 2012]. Note that the estimated factors in Figure A1 apply for a wave amplitude in 3-D relative to a reference amplitude in 2-D with constant water depth thereby excluding more complex geometries and bathymetries.

[70] The next two model effects shown in Figure A1 are investigated in this study, namely the slide model and the three block model parameters. Both effects are found to be significant: the effect of the slide type changes the wave amplitude by up to a factor of 0.43 to 1.76 (Figure 12d). The three block model parameters are included in empirical equations for the first time herein and they change the wave amplitude by up to a factor of two (Table 3). Because both these model effects were previously not considered in empirical equations, they are a potential source of discrepancies between studies.

[71] The model effect wave parameter definition in Figure A1 includes that an empirical equation, say for the maximum wave amplitude $a_{\mathrm{M}}$, is in some studies only valid 


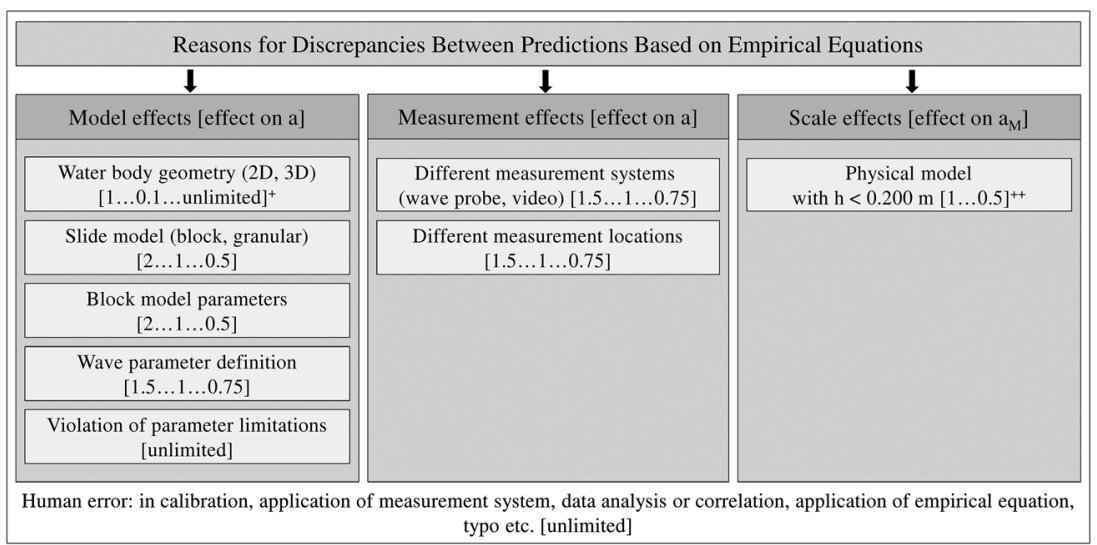

Figure A1. Reasons for discrepancies between different empirical equations based on physical model studies and their estimated effect, expressed as a factor applied on a reference wave amplitude $a$; ${ }^{+}$factor for a wave amplitude in 3-D relative to a reference amplitude in 2-D with constant water depth excluding more complex geometries and bathymetries; 1 may occur in the slide impact zone and $0.1 \ldots$. unlimited in the wave propagation zone; ${ }^{++} 1$ may occur for $h \geq 0.200 \mathrm{~m}$ and the factor 0.5 is an approximation for a water depth of $h=0.075 \mathrm{~m}$.

if it occurs at the primary wave [Monaghan and Kos, 2000; Mohammed and Fritz, 2012] while other studies, including the present one, define $a_{\mathrm{M}}$ over all waves in the wave train because $a_{\mathrm{M}}$ does not necessarily occur at the primary wave. Furthermore, in studies based on video recordings, the wave length is directly observed whereas for wave probes the wave length is indirectly deduced based on the measured wave period resulting in different parameter definitions. It is estimated that the different wave parameter definitions may affect $a$ by a factor of $1.5 \ldots 1 \ldots 0.75$.

[72] Violation of parameter limitations is the last model effect, which may cause discrepancies. Empirical equations are developed for an investigated parameter range and a function representing the data within this range may not be applied outside these limitations. This model effect also considers where a piston-type model with $\alpha=0$ [Noda, 1970] is applied on a mass propagating on a slope. In this case, the limitation for the hill slope angle $\alpha=0$ is violated.

[73] Measurement effects are due to nonidentical measurement techniques being used for data collection, and they form the second category in Figure A1, including different measurement systems and locations. Most studies measured the wave features with capacitance or resistance type wave probes [e.g., Zweifel et al., 2006; Panizzo et al., 2005b] while Ataie-Ashtiani and Nik-Khah [2008] used pressure transducers and the analysis of Monaghan et al. [2003] is based on video recordings. The different measurement principles are particularly relevant for air-water mixture which often occurs in the slide impact zone. Water splashes and impact crater trims are further likely to affect measurement systems differently.

[74] The measurement location is the second measurement effect shown in Figure A1. The wave probe location does not necessarily coincide with the location where the maximum wave amplitude actually occurs. Dependent on whether or not wave probes are located in the slide impact zone, quite different wave magnitudes may be measured. This effect is estimated to change $a$ by a factor of $1.5 \ldots 1 \ldots 0.75$, provided that the measurements are conducted in reasonable proximity of the slide impact zone.
[75] Scale effects are the last category in Figure A1 and they arise due to the inability to keep each relevant force ratio constant between different scale models [Heller, 2011]. Heller et al. [2008] conducted scale series tests including granular slides in a $0.50 \mathrm{~m}$ wide wave flume with water depths $0.075 \leq h \leq 0.600 \mathrm{~m}$. Scale effects affected the maximum wave amplitude $a_{\mathrm{M}}$ by up to $56 \%$. To keep scale effects in relation to $a_{\mathrm{M}}$ below $2 \%$, the Reynolds number $\mathrm{R}=g^{1 / 2} h^{3 / 2} / \nu_{\mathrm{w}}$ and the Weber number $\mathrm{W}=\rho_{\mathrm{w}} g h^{2} / \sigma_{\mathrm{w}}$ have to be $\mathrm{R} \geq 300,000$ and $\mathrm{W} \geq 5000$, with kinematic viscosity $v_{\mathrm{W}}$, surface tension $\sigma_{\mathrm{w}}$, and water density $\rho_{\mathrm{w}}$. Those conditions correspond to approximately $h \geq 0.200 \mathrm{~m}$. Scale effects may be acceptable for a study if only a fraction of the tests is conducted at $h<0.200 \mathrm{~m}$; however, they may significantly affect the overall results of studies such as Walder et al. [2003] with $0.051 \leq h \leq 0.130 \mathrm{~m}$ or Heller et al. [2012] with $h=0.100 \mathrm{~m}$. The authors of the latter study were mainly interested in relative results between different small-scale geometries, and it was argued that scale effects mostly cancel out for such relative results.

\section{Appendix B: Application Example}

[76] The following example shows how the present results resolve discrepancies between different model studies. It quantifies the difference in wave height $H(x)$, due to the three block model parameters, between tests of the present study and tests of Kamphuis and Bowering [1972]. The selected parameters of the present study are $\mathrm{P}=1.0, X=30.0$, $B=0.98, \phi=90^{\circ}(\Phi=1.0)$, and a circular transition $\left(T_{\mathrm{s}}=1.0\right)$, whereas the selected parameters from the tests of Kamphuis and Bowering [1972] are $\mathrm{P}=1.0, X=30.0, B=0.98$ (assumed), $\phi=30.0(\Phi=0.71)$, no transition (Table 1) with abrupt stop with assumed slide volume $\forall_{\mathrm{s}}=0.075 \mathrm{~m}^{3}$, slide thickness $s=0.250 \mathrm{~m}$, and water depth $h=0.300 \mathrm{~m}\left(T_{\mathrm{s}}=0.37\right)$. An approximation for the difference in wave height is found with equation (7) applied to both parameter sets resulting in $\left(1.0 \cdot 30^{-1 / 3} 0.98 \cdot 1.0 \cdot 1.0^{1 / 2}\right)^{9 / 10} /\left(1.0 \cdot 30^{-1 / 3} 0.98 \cdot 0.71 \cdot 0.49^{1 / 2}\right)^{9 / 10}=1.88$. The deviation of $88 \%$ in wave height between the present study and the study of Kamphuis and Bowering [1972] can therefore be attributed to the block model parameters. 


\section{HELLER AND SPINNEKEN: IMPROVED LANDSLIDE-TSUNAMI PREDICTION}

[77] Heller and Hager [2010] directly compared the outcome of their predictive equations with 11 studies for the Lituya Bay case [Miller, 1960]. At the time it was not understood how 2-D block model studies can predict smaller waves (e.g., $a_{\mathrm{M}}=111 \mathrm{~m}$ after Monaghan and Kos [2000]; $a_{\mathrm{M}}=83 \mathrm{~m}$ computed after Walder et al. [2003]) than granular slide models $\left(a_{\mathrm{M}}=143 \mathrm{~m}\right.$ after Heller and Hager [2010]). Common reasons such as scale effects or different measurement systems (appendix A) could not fully explain these discrepancies. This open question is now resolved given that block model slides are indeed able to generate smaller waves than granular slides.

[78] Acknowledgment. The position of VH is funded by an Imperial College London Junior Research Fellowship.

\section{Notation}

$a=$ wave amplitude, $\mathrm{m}$;

$a_{\mathrm{M}}=$ maximum wave amplitude, $\mathrm{m}$;

$b=$ channel width, m;

$b_{\mathrm{s}}=$ slide width, $\mathrm{m}$;

$B=$ blockage ratio $B=b_{\mathrm{s}} / b$;

$c=$ wave celerity, $\mathrm{m} / \mathrm{s}$;

$\mathrm{F}=$ slide Froude number $\mathrm{F}=V_{\mathrm{s}} /(g h)^{1 / 2}$;

$g=$ gravitational acceleration, $\mathrm{m} / \mathrm{s}^{2}$;

$h=$ still water depth, m;

$H=$ wave height, m;

$H_{\mathrm{M}}=$ maximum wave height, m;

$l_{\mathrm{s}}=$ slide length, $\mathrm{m}$;

$L=$ wave length, $\mathrm{m}$;

$m_{\mathrm{s}}=$ slide mass, $\mathrm{kg}$;

$M=$ relative slide mass $M=m_{\mathrm{s}} /\left(\rho_{\mathrm{w}} b_{\mathrm{s}} h^{2}\right)$;

$\mathrm{P}=$ impulse product parameter $\mathrm{P}=\mathrm{FS}^{1 / 2} M^{1 / 4}\{\cos [(6 /$ 7) $\alpha]\}^{1 / 2}$;

$r=$ radial distance from the slide impact zone, $\mathrm{m}$;

$\mathrm{R}=$ Reynolds number $\mathrm{F}=g^{1 / 2} h^{3 / 2} / v_{\mathrm{w}}$;

$R^{2}=$ coefficient of determination;

$s=$ slide thickness, $\mathrm{m}$;

$S=$ relative slide thickness $S=s / h$;

$t=$ time after slide impact, $\mathrm{s}$;

$t_{\mathrm{s}}=$ characteristic time of submerged landslide motion, $\mathrm{s}$;

$T=$ wave period, $\mathrm{s}$;

$T_{\mathrm{M}}=$ maximum wave period, $\mathrm{s}$;

$T_{\mathrm{s}}=$ expression considering transition type $T_{\mathrm{s}}=$ $t_{\mathrm{s}} /\left\{\left[h+\mathrm{V}_{\mathrm{s}} /\left(s b_{\mathrm{s}}\right)\right] / V_{\mathrm{s}}\right\}$;

$\mathrm{U}=$ Ursell parameter $\mathrm{U}=H L^{2} / h^{3}$;

$V_{\mathrm{s}}=$ slide centroid impact velocity, $\mathrm{m} / \mathrm{s}$;

$V_{\mathrm{s}}=$ slide volume, $\mathrm{m}^{3}$;

$\mathrm{W}=$ Weber number $\mathbf{W}=\rho_{\mathrm{w}} g h^{2} / \sigma_{\mathrm{w}}$;

$x=$ streamwise distance from the slide impact zone, $\mathrm{m}$;

$x^{\prime}=$ coordinate along hill slope, $\mathrm{m}$;

$X=$ relative streamwise distance from the slide impact zone $X=x / h$;

$z=$ vertical coordinate, $\mathrm{m}$;

$\alpha=$ slide impact angle, i.e., hill slope angle, ${ }^{\circ}$;

$\Delta=$ difference between two wave parameters, $\%$;

$\phi=$ slide front angle, ${ }^{\circ}$;

$\phi+\alpha=$ slide front orientation angle, ${ }^{\circ}$;

$\Phi=$ expression considering slide front angle $\Phi=\sin ^{1 / 2} \phi$;

$\eta=$ water surface displacement, $\mathrm{m}$;

$v_{\mathrm{w}}=$ kinematic viscosity of water, $\mathrm{m}^{2} / \mathrm{s}$;

$\rho_{\mathrm{s}}=$ slide density, $\mathrm{kg} / \mathrm{m}^{3}$; $\rho_{\mathrm{w}}=$ water density, $\mathrm{kg} / \mathrm{m}^{3} ;$ and

$\sigma_{\mathrm{w}}=$ surface tension of water, $\mathrm{kg} / \mathrm{s}^{2}$.

\section{Subscript}

adjusted $=$ adjusted;

block = block;

granular = granular;

$\mathrm{m}=$ mean;

$\mathrm{M}=$ maximum;

$\mathrm{s}=$ submerged, slide; and

$\mathrm{w}=$ water.

\section{Abbreviation}

LDS $=$ Laser distance sensor

N.A. $=$ Not available

2-D = two-dimensional

$3-\mathrm{D}=$ three-dimensional

\section{References}

Abadie, S.M., J. C. Harris, S.T. Grilli, and R. Fabre (2012), Numerical modeling of tsunami waves generated by the flank collapse of the Cumbre Vieja Volcano (La Palma, Canary Islands): Tsunami source and near field effects, J. Geophys. Res., 117, C05030.

Abadie, S., D. Morichon, S. Grilli, and S. Glockner (2010), Numerical simulation of waves generated by landslides using a multiple-fluid Navier-Stokes model, Coast. Eng., 57(9), 779-794, doi:10.1016/j. coastaleng.2010.03.003.

Ataie-Ashtiani, B., and A. Nik-Khah (2008), Impulsive waves caused by subaerial landslides, Environ. Fluid Mech., 8, 263-280, doi:10.1007/ s10652-008-9074-7.

Boussinesq, J. (1872), Théorie des ondes et des remous que se propagent le long d'un canal rectangulaire horizontal, en communiquant au liquid contenu dans ce canal des vitesses sensiblement pareilles de la surface au fond, J. Math. Pures Appl., 17(2), 55-108 (in French).

Cruden, D.M., and D.J. Varnes (1996), Landslide types and processes, in Landslides: Special report 247, edited by A. K. Turner and R. L. Schuster, pp. 36-75, Transportation Research Board, Washington, D.C.

Di Risio, M., and P. Sammarco (2008), Analytical modeling of landslidegenerated waves, J. Waterw. Port C-ASCE, 134(1), 53-60, doi:10.1061/ (ASCE)0733-950X(2008)134:1(53).

Fritz, H.M., W.H. Hager, and H.-E. Minor (2004), Near field characteristics of landslide generated impulse waves, J. Waterw. Port C-ASCE, 130(6), 287-302, doi:10.1061/(ASCE)0733-950X(2004)130:6(287).

Fuchs, H., M. Pfister, R. Boes, S. Perzlmaier, and R. Reindl (2011), Impulswellen infolge Lawineneinstoss in den Speicher Kühtai, Wasserwirtschaft, 101(1-2), 54-60 (in German).

Giachetti, T., R. Paris, K. Kelfoun, and F.J. Pérez-Torrado (2011), Numerical modelling of the tsunami triggered by the Güimar debris avalanche, Tenerife (Canary Islands): Comparison with field-based data, Mar. Geol., 284(1-4), 189-202, doi:10.1016/j.margeo.2011.03.018.

Heinrich, P. (1992), Nonlinear water waves generated by submarine and aerial landslides, J. Waterw. Port C-ASCE, 118(3), 249-266, doi:10.1061/ (ASCE)0733-950X(1992)118:3(249).

Heller, V. (2011), Scale effects in physical hydraulic engineering models, J. Hydraul. Res., 49(3), 293-306, doi:10.1080/00221686.2011. 578914.

Heller, V., and W.H. Hager (2010), Impulse product parameter in landslide generated impulse waves, J. Waterw. Port C-ASCE, 136(3), 145-155, doi:10.1061/(ASCE)WW.1943-5460.0000037.

Heller, V., and W.H. Hager (2011), Wave types of landslide generated impulse waves, Ocean Eng., 38(4), 630-640, doi:10.1016/j.oceaneng.2010.12.010.

Heller, V., and R.D. Kinnear (2010), Discussion of "Experimental investigation of impact generated tsunami; related to a potential rock slide, Western Norway" by G. Sælevik, A. Jensen, G. Pedersen [Coastal Eng. 56(2009) 897-906], Coast. Eng., 57(8), 773-777, doi:10.1016/j.coastaleng.2010.02.008.

Heller, V., and J. Spinneken (2012), Optimising landslide-tsunami prediction based on physical model tests, Proc., $2^{\text {nd }}$ European conference of IAHR, paper B22, Munich, IAHR, Madrid.

Heller, V., W.H. Hager, and H.-E. Minor (2008), Scale effects in subaerial landslide generated impulse waves, Exp. Fluids, 44, 691-703, doi:10.1007/s00348-007-0427-7. 


\section{HELLER AND SPINNEKEN: IMPROVED LANDSLIDE-TSUNAMI PREDICTION}

Heller, V., W.H. Hager, and H.-E. Minor (2009), Landslide generated impulse waves in reservoirs - Basics and computation. VAW-Mitteilung 211, edited by R. Boes, ETH Zurich, Zurich.

Heller, V., M. Moalemi, R.D. Kinnear, and R.A. Adams (2012), Geometrica effects on landslide-generated tsunamis, J. Waterw. Port C-ASCE, 138(4), 286-298, doi:10.1061/(ASCE)WW.1943-5460.0000130.

Huber, A. (1982), Impulse waves in Swiss lakes as a result of rock avalanches and bank slides. Experimental results for the prediction of the characteristic numbers of these waves. Proc., 14th Congrès des Grands Barrages, Rio de Janeiro, ICOLD, Paris, 455-476.

Huber, A., and W.H. Hager (1997), Forecasting impulse waves in reservoirs. Proc., 19th Congrès des Grands Barrages, Florence, ICOLD, Paris, 993-1005.

Kamphuis, J.W., and R.J. Bowering (1972), Impulse waves generated by landslides. Proc., 12th Coastal Engineering Conf., Vol. 1, ASCE, New York, 575-588.

Liu, P.L.-F., T.-R. Wu, F. Raichlen, C.E. Synolakis, and J.C. Borrero (2005), Runup and rundown generated by three-dimensional sliding masses, J. Fluid Mech., 536, 107-144, doi:10.1017/S0022112005004799.

Løvholt, F., G. Pedersen, and G. Gisler (2008), Oceanic propagation of a potential tsunami from the La Palma Island, J. Geophys. Res., 113, C09026.

Lynett, P., and L.-F. Liu (2005), A numerical study of the run-up generated by three-dimensional landslides, J. Geophys. Res., 110, C03006.

Miller, D.J. (1960), Giant waves in Lituya Bay, Alaska. Geological Survey Professional Paper No. 354-C, U.S. Government Printing Office, Washington, D.C

Mohammed, F., and H.M. Fritz (2012), Physical modeling of tsunamis generated by three-dimensional deformable granular landslides, J. Geophys. Res., 117, C11015.

Monaghan, J.J., and A. Kos (2000), Scott Russell's wave generator, Phys. Fluids, 12(3), 622-630, doi:10.1063/1.870269.

Monaghan, J.J., A. Kos, and N. Issa (2003), Fluid motion generated by impact, J. Waterw. Port C-ASCE, 129(6), 250-259, doi:10.1061/(ASCE) 0733-950X(2003)129:6(250).

Müller, D. (1995), Auflaufen und Überschwappen von Impulswellen an Talsperren. VAW-Mitteilung 137, edited by D. Vischer, ETH Zurich, Zurich (in German)

Müller, L. (1964), The rock slide in the Vajont Valley, Rock Mech. Eng. Geol., 2(3-4), 148-212.
Noda, E. (1970), Water waves generated by landslides, Journal of the Waterways, Harbors and Coastal Engineering Division ASCE, 96 (WW4), 835-855.

Panizzo, A., G. Bellotti, and P. De Girolamo (2002), Application of wavelet transform analysis to landslide generated waves, Coast. Eng., 44(4), 321-338, doi:10.1016/S0378-3839(01)00040-0.

Panizzo, A., P. De Girolamo, M. Di Risio, A. Maistri, and A. Petaccia (2005a), Great landslide events in Italian artificial reservoirs, Nat. Hazard Earth Sys., 5(5), 733-740.

Panizzo, A., P. De Girolamo, and A. Petaccia (2005b), Forecasting impulse waves generated by subaerial landslides, J. Geophys. Res., 110, C12025.

Quecedo, M., M. Pastor, and M.I. Herreros (2004), Numerical modeling of impulse wave generated by fast landslides, Int. J. Numer. Methods Eng., 59, 1633-1656, doi:10.1002/nme.841.

Sælevik, G., A. Jensen, and G. Pedersen (2009), Experimental investigation of impact generated tsunami; related to a potential rock slide, Western Norway, Coast. Eng., 56(9), 897-906, doi:10.1016/j.coastaleng.2009.04.007.

Slingerland, R.L., and B. Voight (1979), Occurrences, properties and predictive models of landslide-generated impulse waves, in Rockslides and avalanches, vol. 2, edited by B. Voight, pp. 317-397, Elsevier, Amsterdam.

Ursell, F. (1953), The long-wave paradox in the theory of gravity waves, P. Camb. Philol. Soc., 49, 685-694, doi:10.1017/S0305004100028887.

Walder, J.S., P. Watts, O.E. Sorensen, and K. Janssen (2003), Tsunamis generated by subaerial mass flows, J. Geophys. Res., 108(B5), 2236(2).

Watt, S.F.L., et al. (2012), Combinations of volcanic-flank and seafloor-sediment failure offshore Montserrat, and their implications for tsunami generation, Earth Planet. Sc. Let., (319-320), 228-240, doi:10.1016/j.eps1.2011.11.032.

Western Canada Hydraulic Laboratories (1970), Hydraulic model studies Wave action generated by slides into Mica Reservoir - British Columbia. Report, Western Canada Hydraulic Laboratories, Vancouver.

Wiegel, R.L., E.K. Noda, E.M. Kuba, D.M. Gee, and G.F. Tornberg (1970), Water waves generated by landslides in reservoirs, Journal of the Waterways and Harbors Division ASCE, 96(WW2), 307-333.

Zweifel, A. (2004), Impulswellen: Effekte der Rutschdichte und der Wassertiefe. PhD Thesis 15596, ETH Zurich, Zurich (in German).

Zweifel, A., W.H. Hager, and H.-E. Minor (2006), Plane impulse waves in reservoirs, J. Waterw. Port C-ASCE, 132(5), 358-368, doi:10.1061/ (ASCE)0733-950X(2006)132:5(358). 